\title{
An R2R3 MYB transcription factor associated with regulation of the anthocyanin biosynthetic pathway in Rosaceae
}

\author{
Kui Lin-Wang ${ }^{1}$, Karen Bolitho ${ }^{1}$, Karryn Grafton ${ }^{1}$, Anne Kortstee ${ }^{2}$, Sakuntala Karunairetnam ${ }^{1}$, Tony K McGhie ${ }^{3}$, \\ Richard V Espley ${ }^{1}$, Roger P Hellens ${ }^{1}$, Andrew C Allan ${ }^{1 *}$
}

\begin{abstract}
Background: The control of plant anthocyanin accumulation is via transcriptional regulation of the genes encoding the biosynthetic enzymes. A key activator appears to be an R2R3 MYB transcription factor. In apple fruit, skin anthocyanin levels are controlled by a gene called MYBA or MYB1, while the gene determining fruit flesh and foliage anthocyanin has been termed MYB10. In order to further understand tissue-specific anthocyanin regulation we have isolated orthologous MYB genes from all the commercially important rosaceous species.
\end{abstract}

Results: We use gene specific primers to show that the three MYB activators of apple anthocyanin (MYB10/MYB1/ MYBA) are likely alleles of each other. MYB transcription factors, with high sequence identity to the apple gene were isolated from across the rosaceous family (e.g. apples, pears, plums, cherries, peaches, raspberries, rose, strawberry). Key identifying amino acid residues were found in both the DNA-binding and C-terminal domains of these MYBs. The expression of these MYB10 genes correlates with fruit and flower anthocyanin levels. Their function was tested in tobacco and strawberry. In tobacco, these MYBs were shown to induce the anthocyanin pathway when co-expressed with bHLHs, while over-expression of strawberry and apple genes in the crop of origin elevates anthocyanins.

Conclusions: This family-wide study of rosaceous R2R3 MYBs provides insight into the evolution of this plant trait. It has implications for the development of new coloured fruit and flowers, as well as aiding the understanding of temporal-spatial colour change.

\section{Background}

The Rosaceae is an economically important group of cultivated plants, which includes fruit-producing genera such as Malus (apples), Pyrus (pears), Prunus (e.g. peach, plums, apricots), Fragaria (strawberries), and Rubus (raspberry, blackberry, boysenberry), as well as ornamental plants such as Rosa (rose). In these fruits and flowers, colour is a key quality trait and is often caused by anthocyanin. Anthocyanins are water-soluble pigments that belong to the flavonoid family of compounds giving red, blue and purple colours in a range of flowers, fruits, foliage, seeds and roots [1]. Anthocyanins are involved in a wide range of functions, such as the

\footnotetext{
* Correspondence: andrew.allan@plantandfood.co.nz

'The New Zealand Institute for Plant \& Food Research Ltd, (Plant and Food Research), Mt Albert Research Centre, Private Bag 92169, Auckland, New
} Zealand

(c) 2010 Lin-Wang et al; licensee BioMed Central Ltd. This is an Open Access article distributed under the terms of the Creative Commons Attribution License (http://creativecommons.org/licenses/by/2.0), which permits unrestricted use, distribution, and reproduction in any medium, provided the original work is properly cited. attraction of pollinators, seed dispersal, protection against UV light damage, and pathogen attack [2-5]. Recently, research on anthocyanins has intensified because of their potential benefits to human health, including protection against cancer, inflammation, coronary heart diseases and other age-related diseases [6-11].

In plants, the structural genes of the flavonoid biosynthetic pathway are largely regulated at the level of transcription. In all species studied to date, the regulation of the expression of anthocyanin biosynthetic genes are through a complex of MYB transcription factors (TF), basic helix-loop-helix (bHLH) TFs and WD-repeat proteins (the MYB-bHLH-WD40 "MBW" complex; [12]). A model has been proposed for the activation of structural pigmentation genes, with regulators interacting with each other to form transcriptional complexes in 
conjunction with the promoters of structural genes [13]. For example, the R2R3 MYB C1 protein, that regulates the anthocyanin pathway in maize, interacts with a bHLH TF (either of the genes termed $B$ or $R$ ) to activate the promoter of dihydroflavonol reductase (DFR). In contrast, the R2R3 MYB P protein, which regulates the phlobaphene pathway in maize, can activate the same promoter without a bHLH TF [14].

MYB TFs can be classified into three subfamilies based on the number of highly conserved imperfect repeats in the DNA-binding domain including R3 MYB (MYB1R) with one repeat, R2R3 MYB with two repeats, and R1R2R3 MYB (MYB3R) with three repeats $[15,16]$. Among these MYB transcription factors, R2R3-MYBs constitute the largest TF gene family in plants, with 126 R2R3 MYB genes identified in Arabidopsis [17]. Those associated with up-regulation of the anthocyanin pathway are R2R3 MYBs. Over-expression of the AtPAP1 gene (AtMYB75, At1 g56650) results in the accumulation of anthocyanins in Arabidopsis [18]. Several repressors of the phenylpropanoid pathway, and perhaps anthocyanins specifically, are also MYB TFs, including an R2R3 MYB repressor from strawberry FaMYB1 [19], Arabidopsis AtMYB6, 4, and 3 [20], Antirrhinum AmMYB308 [21], and a one repeat MYB in Arabidopsis, AtMYBL2 [22,23]. How the repressor MYBs interact with the MBW transcriptional complex is beginning to be elucidated [22,23].

Based on the phylogenetic relationship between Arabidopsis R2R3 MYB TFs and anthocyanin-related MYBs of other species, it appears that anthocyanin-regulating R2R3 MYBs fall into one or two clades $[17,24,25]$. Anthocyanin-regulating MYBs have been isolated from many species, including Arabidopsis AtMYB75 or PAP1, AtMYB90 or PAP2, AtMYB113 and AtMYB114 [26], Solanum lycopersicum ANT1 [27], Petunia hybrida AN2 [28], Capsicum annuum A [29], Vitis vinifera VvMYB1a [30], Zea mays $P$ [31], Oryza saliva C1 [32], Ipomoea batatas IbMYB1 [33], Anitirrhinum majus ROSEA1, ROSEA2 and VENOSA [34], Gerbera hybrid GhMYB10 [35], Picea mariana MBF1 [36], Garcinia mangostana GmMYB10 [37], Malus × domestica MdMYB10, $\operatorname{Md} M Y B 1 / \operatorname{Md} M Y B A[24,38,39]$, and Gentian GtMYB3 [40].

For rosaceous species, MYBs that regulate the genes of the anthocyanin pathway have been examined in apple and strawberry. In apple (Malus $\times$ domestica) MYB10 was isolated from red-fleshed apple 'Red Field' [24], and showed a strong correlation between the expression of MYB10 and apple anthocyanin levels during fruit development. Transgenic apple lines constitutively expressing $M Y B 10$ produced highly pigmented shoots. Two more apple TFs, MYB1 and MYBA, were also reported to regulate genes in the anthocyanin pathway in red-skinned fruit [38,39]. Both $M Y B 1$ and $M Y B A$ share identical sequences [38], while $M Y B 10$ and $M Y B 1$ genes are located at very similar positions on linkage group 9 of the apple genetic map [41]. In strawberry (Fragaria $\times$ ananassa), the R2R3 MYB TF FaMYB1 plays a key role in down-regulating the biosynthesis of anthocyanins and flavonols [19].

In this current study, we used an allele-specific PCR primer approach to show that $M d M Y B 1 / M d M Y B A /$ $M d M Y B 10$ are highly likely to be allelic in the apple genome. We then isolated genes with high sequence similarity to MYB10 from 20 species within the Rosaceae. Sequence and functional characterization of these genes provides insight into the evolution of this TF, within a plant family where higher levels of pigmentation has been selected for during the process of domestication. Expression analysis during the fruit development, and functional testing using transient assays and transgenic plants suggest that these R2R3 MYBs are responsible for controlling anthocyanin biosynthesis in these crops.

\section{Results}

\section{The MdMYB10/MdMYB1/MdMYBA genes are likely to be} allelic

Three highly homologous apple genes, MYB10 [24], MYB1 [39] and MYBA [38], have been reported in different cultivars of apple. In order to ascertain whether, in any given cultivar, these represent different genes or are alleles of the one gene, we designed PCR primers to amplify a region of genomic DNA common to all three of these genes, spanning a region from the promoter through to exon 1 of the published sequences. This region produces an amplification length polymorphism distinguishing the MYB10 allele present in red-fleshed cultivars from white fleshed types [42]. The amplification products from a range of apple varieties are shown in Figure 1A. One amplification product of approximately $900 \mathrm{bp}$ is observed for the white-fleshed varieties Pacific Rose ${ }^{\mathrm{m}}$, 'Royal Gala', and 'Granny Smith'. Two amplification products, of approximately $900 \mathrm{bp}$ and $1000 \mathrm{bp}$, were observed in red-fleshed apple varieties such as 'Red Field', 'Niedzwetzkyana', and 'Robert's Crab'. With red-fleshed varieties, known to be homologous for the red-flesh gene $[41,42]$, only the 1000-bp fragment is amplified. These products represent the $R_{1}$ and $\mathrm{R}_{6}$ alleles previously reported for $M Y B 10$ [42], and suggests that $M Y B 10$ and $M Y B 1$ are alleles, because if they were paralogues there would still be two products in $\mathrm{R}_{6} \mathrm{R}_{6}$ homozygous apples.

While these end-point PCR amplifications are not quantitative, the fluorescence from ethidium bromide (EtBr) indicated that in those tissues where both 900and 1000-bp fragments are amplified, these molecules 


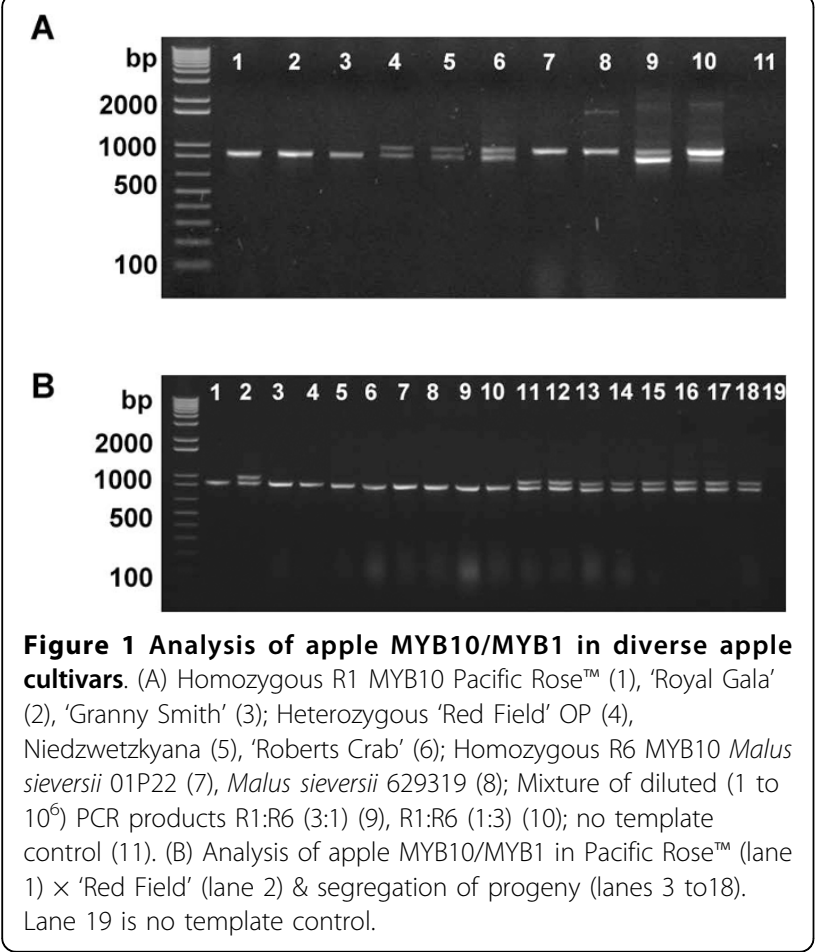

are likely to be in equivalent molar quantity within the genome. This is based on the observation that when a mixture of diluted PCR products from the 900-bp and 1000 -bp fragments are mixed in ratios of $3: 1$ or $1: 3$ respectively, the EtBr fluorescence of the end-point PCR amplifications reflects the corresponding molar ratios (Figure 1A). Furthermore, PCR analysis of the progeny from crosses made between the $R_{1}$ homozygous Pacific $\operatorname{Rose}^{\mathrm{Tm}}$ cultivar and the heterozygous $\mathrm{R}_{1} \mathrm{R}_{6}$ 'Red Field' shows segregation of the homozygous $R_{1}$ allele and the heterozygous $\mathrm{R}_{1}$ and $\mathrm{R}_{6}$ alleles (Figure $1 \mathrm{~B}$ ). If $M Y B 1$ and $M Y B 10$ were different genes, band intensity ratios of 3:1 would be possible but as only 1:1 ratios are observed, MYB1 and MYB10 are likely to be allelic, representing the $\mathrm{R}_{1}$ and $\mathrm{R}_{6}$ alleles.

\section{Isolation of MYB10 homologues from the major rosaceous crop species}

We isolated both cDNA and genomic DNA from 20 rosaceous species and, using a gene-specific primer approach based on the apple $M Y B 10$ gene sequence, generated PCR fragments for cloning into sequencing vectors. Fragments with sequence similarity to $M Y B 10$ were used to obtain full-length sequences for further functional testing. This approach worked well for all the members of the Maloideae subfamily (including apple, quince, loquat, medlar and pear) and Amygdaloideae subfamily (including apricot, damson, cherry, plum, almond and peach), but not for species of the Rosoideae subfamily (rose, strawberry and raspberry). For Rosoideae, we required additional steps involving 5' and 3' GeneRace of mRNA (GeneRacer Kit, Invitrogen), with degenerate primers designed to the consensus DNA sequence of the anthocyanin-related R2R3 MYB DNA binding domain. The rosaceous MYB transcription factors isolated, using these approaches, are shown in Table 1, and predicted protein sequence is shown in Figure 2.

For both protein sequence and coding DNA sequence (CDS) of rosaceous MYBs, the percentage of identity to Arabidopsis AtMYB75 (PAP1, AT1G56650) varied from 58 to $64 \%$, and 40 to $49 \%$, respectively. The length of CDS and protein sequence was similar between each species analysed, but the length of genomic DNA (gDNA) sequence varied significantly from $1122 \mathrm{bp}$ (Rosa hybrida) to 4055 bp (Malus $\times$ domestica, Table $1)$. This is due almost entirely to the variable length of intron 2, which ranges from 82 bp (AtMYB90) to 3000 bp (MdMYB1). A schematic of $M Y B 10$-like genes from rosaceous species is shown in Additional File 1 . The large size of intron 2 in apple correlates with its higher DNA content than close relatives; apple has almost 2.5 times more DNA mass than pear [43 ]http://www.kew. org/cval/homepage.html. Intron 2 of apple $M Y B 10$ is 2995 bp, compared with 487 bp in pear (Additional File 1B).

When the region of homology, corresponding to the MYB R2R3 domain, was used to generate a phylogenic tree, all the genes clustered with known anthocyaninrelated MYBs (Figure 3A). Furthermore, the MYB genes clustered according to their taxonomic relationships in the Rosaceae (Figure 3B). For the Maloideae (apple, pear, quince, loquat and medlar), all clustered together into a clade. For the Amygdaloideae (plum, cherry, almond, apricot, peach and damson), all were clustered into another clade. Raspberry, strawberry and rose are the members of the Rosoideae and they all clustered together. While the Maloideae and Amygdaloideae clustered closely together, the Rosoideae clustered more distantly.

\section{Sequence signatures specific for anthocyanin-related MYBs}

The large gene family of R2R3 MYB proteins was examined using conserved regions of homology. Over 172 proteins were included; all Arabidopsis R2R3 MYBs, 38 other dicot anthocyanin-promoting MYBs, including apple MYB8, MYB9 and MYB11 (GenBank DQ267899, DQ267900, and DQ074463 respectively), strawberry anthocyanin repressor MYB1, as well as anthocyaninrelated MYBs from four monocots and one gymnosperm. All the MYBs associated with promoting anthocyanin biosynthesis from dicot species cluster 
Table 1 Anthocyanin activating R2R3 MYBs transcription factors

\begin{tabular}{|c|c|c|c|c|c|c|c|c|}
\hline Species & $\begin{array}{c}\text { Current } \\
\text { name }\end{array}$ & $\begin{array}{c}\text { Genebank } \\
\text { number }\end{array}$ & $\begin{array}{l}\% \text { similarity to AtMYB75 } \\
\text { protein }\end{array}$ & $\begin{array}{l}\% \text { identity to } \\
\text { AtMYB75 }\end{array}$ & $\begin{array}{c}\text { gDNA } \\
\text { (bp) }\end{array}$ & $\begin{array}{l}\text { CDS } \\
\text { (bp) }\end{array}$ & $\begin{array}{l}\text { protein } \\
\text { (aa) }\end{array}$ & $\begin{array}{c}\text { Intron2 } \\
\text { (bp) }\end{array}$ \\
\hline Arabidopsis thaliana & $\begin{array}{c}\text { PAP1 } \\
\text { AtMYB75 }\end{array}$ & AF325123 & 100 & 100 & 1376 & 747 & 248 & 89 \\
\hline Arabidopsis thaliana & $\begin{array}{l}\text { PAP2 } \\
\text { AtMYB90 }\end{array}$ & NM_105310 & 88 & 84 & 1349 & 750 & 249 & 82 \\
\hline $\begin{array}{l}\text { Solanum lycopersicum } \\
\text { (tomato) }\end{array}$ & ANT1 & AY348870 & 56 & 41 & $\mathrm{n} / \mathrm{a}$ & 825 & 274 & $\mathrm{n} / \mathrm{a}$ \\
\hline Petunia hybrida & AN2 & EF423868 & 66 & 45 & $\mathrm{n} / \mathrm{a}$ & 768 & 255 & $\mathrm{n} / \mathrm{a}$ \\
\hline Capsicum annuum & A & AJ608992 & 64 & 44 & $\mathrm{n} / \mathrm{a}$ & 789 & 262 & $\mathrm{n} / \mathrm{a}$ \\
\hline Vitis vinifera (grape) & VvMYB1a & AB242302 & 58 & 43 & $\mathrm{n} / \mathrm{a}$ & 753 & 250 & $\mathrm{n} / \mathrm{a}$ \\
\hline Zea mays (Maize) & P & AF292540 & 32 & 26 & $\mathrm{n} / \mathrm{a}$ & 1131 & 376 & $\mathrm{n} / \mathrm{a}$ \\
\hline Oryza sativa (Rice) & $\mathrm{C} 1$ & Y15219 & 54 & 33 & $\mathrm{n} / \mathrm{a}$ & 819 & 272 & $\mathrm{n} / \mathrm{a}$ \\
\hline $\begin{array}{c}\text { Ipomoea batatas (Sweet } \\
\text { potato) }\end{array}$ & |bMYB1 & AB258985 & 61 & 44 & 1194 & 750 & 249 & 313 \\
\hline $\begin{array}{l}\text { Antirrhinum majus } \\
\text { (snapdragon) }\end{array}$ & ROSEA1 & DQ275529 & 66 & 52 & $\mathrm{n} / \mathrm{a}$ & 663 & 220 & $\mathrm{n} / \mathrm{a}$ \\
\hline Gerbera hybrid & GMYB10 & AJ554700 & 58 & 44 & $\mathrm{n} / \mathrm{a}$ & 753 & 250 & $\mathrm{n} / \mathrm{a}$ \\
\hline Picea mariana & MBF1 & PMU39448 & 30 & 41 & $\mathrm{n} / \mathrm{a}$ & 1167 & 388 & $\mathrm{n} / \mathrm{a}$ \\
\hline Malus domestica (apple) & MdMYB10 & EU518249 & 60 & 47 & 4050 & 729 & 243 & 2995 \\
\hline Malus domestica (apple) & MdMYB1 & DQ886414 & 60 & 47 & 4055 & 732 & 243 & 3000 \\
\hline Malus sylvestris (crab apple) & MsMYB10 & EU153573 & 60 & 47 & 4036 & 732 & 243 & 2981 \\
\hline Cydonia oblonga (quince) & CoMYB10 & EU153571 & 61 & 47 & 2436 & 738 & 245 & 1418 \\
\hline Eriobotrya japonica (loquat) & EjMYB10 & EU153572 & 59 & 47 & 1520 & 741 & 246 & 498 \\
\hline Mespilus germanica (medlar) & MgMYB10 & EU153574 & 60 & 47 & 2232 & 738 & 245 & 1168 \\
\hline Pyrus communis (Pear) & PCMYB10 & EU153575 & 60 & 47 & 1545 & 735 & 244 & 487 \\
\hline Pyrus pyrifolia (Nashi) & PpyMYB10 & EU153576 & 60 & 47 & 1541 & 735 & 244 & 483 \\
\hline $\begin{array}{l}\text { Pyrus } \times \text { bretschneideri } \\
\text { (Chinese pear) }\end{array}$ & PbMYB10 & EU153577 & 60 & 47 & 1546 & 735 & 244 & 488 \\
\hline Prunus armeniaca (Apricot) & ParMYB10 & EU153578 & 61 & 49 & 2245 & 732 & 243 & 1211 \\
\hline Prunus insititia (Damson) & PiMYB10 & EU153579 & 62 & 49 & 1924 & 732 & 242 & 882 \\
\hline $\begin{array}{l}\text { Prunus domestica (European } \\
\text { plum) }\end{array}$ & PdmMYB10 & EU153580 & 60 & 48 & 2012 & 714 & 237 & 993 \\
\hline Prunus avium (sweet cherry) & PavMYB10 & EU153581 & 61 & 50 & 2223 & 735 & 244 & 1123 \\
\hline Prunus cerasus (sour cherry) & PcrMYB10 & EU153582 & 64 & 46 & 2291 & 678 & 225 & 1196 \\
\hline $\begin{array}{c}\text { Prunus cerasifera (cherry } \\
\text { plum) }\end{array}$ & PcfMYB10 & EU153583 & 61 & 49 & 1960 & 732 & 243 & 926 \\
\hline Prunus dulcis (almond) & PdMYB10 & EU155159 & 61 & 46 & 1796 & 678 & 225 & 812 \\
\hline Prunus persica (peach) & PprMYB10 & EU155160 & 60 & 46 & 1845 & 675 & 224 & 947 \\
\hline $\begin{array}{l}\text { Prunus salicina (Japanese } \\
\text { plum) }\end{array}$ & PsMYB10 & EU155161 & 60 & 49 & 1880 & 732 & 243 & 842 \\
\hline $\begin{array}{c}\text { Fragaria } \times \text { ananassa } \\
\text { (strawberry) }\end{array}$ & FaMYB10 & EU155162 & 62 & 45 & 1685 & 702 & 233 & 899 \\
\hline Fragaria vesca (strawberry) & FvMYB10 & EU155163 & 62 & 44 & 1714 & 705 & 235 & 926 \\
\hline Rosa hybrida (rose) & RhMYB10 & EU155164 & 59 & 40 & 1122 & 750 & 249 & 264 \\
\hline Rubus idaeus (red raspberry) & RiMYB10 & EU155165 & 58 & 43 & 1685 & 654 & 217 & 806 \\
\hline
\end{tabular}

MYB transcription factors, homologous to apple MdMYB10, from all the major rosaceous species (below the middle line), and the published anthocyanin MYB regulators from other species (above the middle line).

within the same clade as PAP1 and other Arabidopsis MYBs of this subgroup (Figure 3A). Monocot sequences, such as $\mathrm{C} 1$ and $\mathrm{P}$, as well as the gymnosperm Picea mariana MBF1, cluster outside this group, suggesting that this clade is dicot-specific. The function of promoting anthocyanin biosynthesis for this subgroup may therefore have evolved after the divergence between dicots and monocots.

To ascertain if there is an identifiable protein motif specific for anthocyanin-promoting MYBs in the N-terminal R2R3 domain, the isolated rosaceous MYBs and other anthocyanin-promoting MYBs (16 from other dicot 


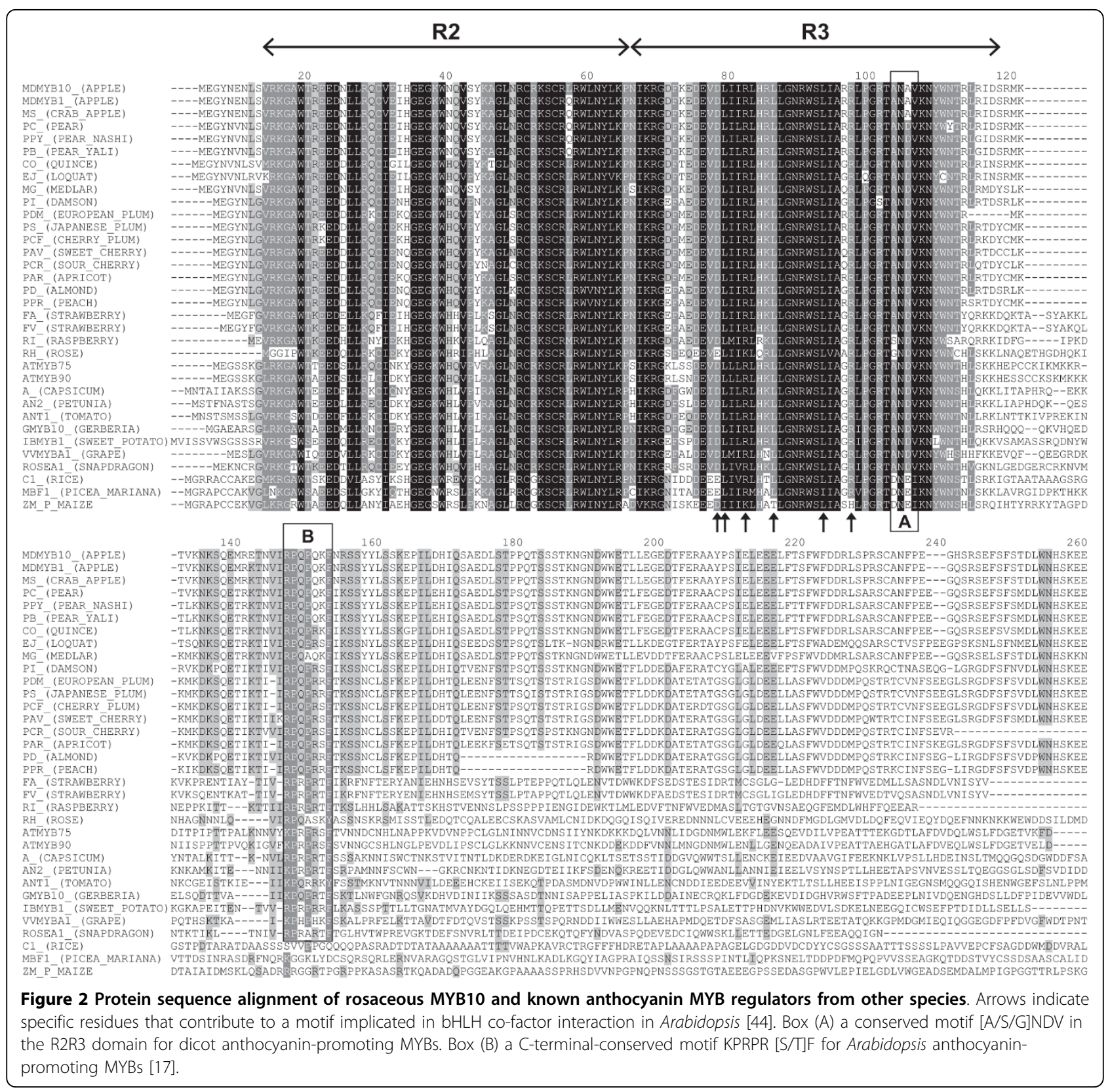

species) were compared with 134 MYB peptide sequences of other clades (Figure 4). Three amino-acid residues (arginine $(\mathrm{R})$, valine $(\mathrm{V})$, alanine $(\mathrm{A})$; marked with arrows in Figure 4A) are conserved for dicot anthocyanin-promoting MYBs at a frequency of 100(R):92(V):90(A). None of these amino-acid residues appeared in the other 134 sequences at the respective position (full dataset in Additional File 2). Another convenient identifier for an anthocyanin-promoting MYB appears to be ANDV (in over $90 \%$ of cases) at position 90 to 93 in the R2R3 domain (Figure 2 Box A and Figure 4B) which is not seen in any other R2R3 MYBs (Additional File 2).
Outside of the DNA-interacting R2R3 domain, most R2R3 MYB proteins have a long C-terminal sequence. In this region of Arabidopsis anthocyanin-promoting MYBs, the motif KPRPR [S/T]F has been identified (Box $B$ in Figure 2) [17], which is not present in other R2R3 MYBs. When anthocyanin-promoting MYB sequences from other species are aligned, this C-terminus consensus motif was still identifiable but with slight variations (Figure 2) to become $[\mathrm{R} / \mathrm{K}] \mathrm{Px}[\mathrm{P} / \mathrm{A} / \mathrm{R}] \mathrm{xx}[\mathrm{F} / \mathrm{Y}]$. Within the subfamilies Maloideae and Amygdeloideae, there was over $70 \%$ similarity of C-terminus. An 18 amino acid deletion occurred in the $\mathrm{C}$-terminus of both 


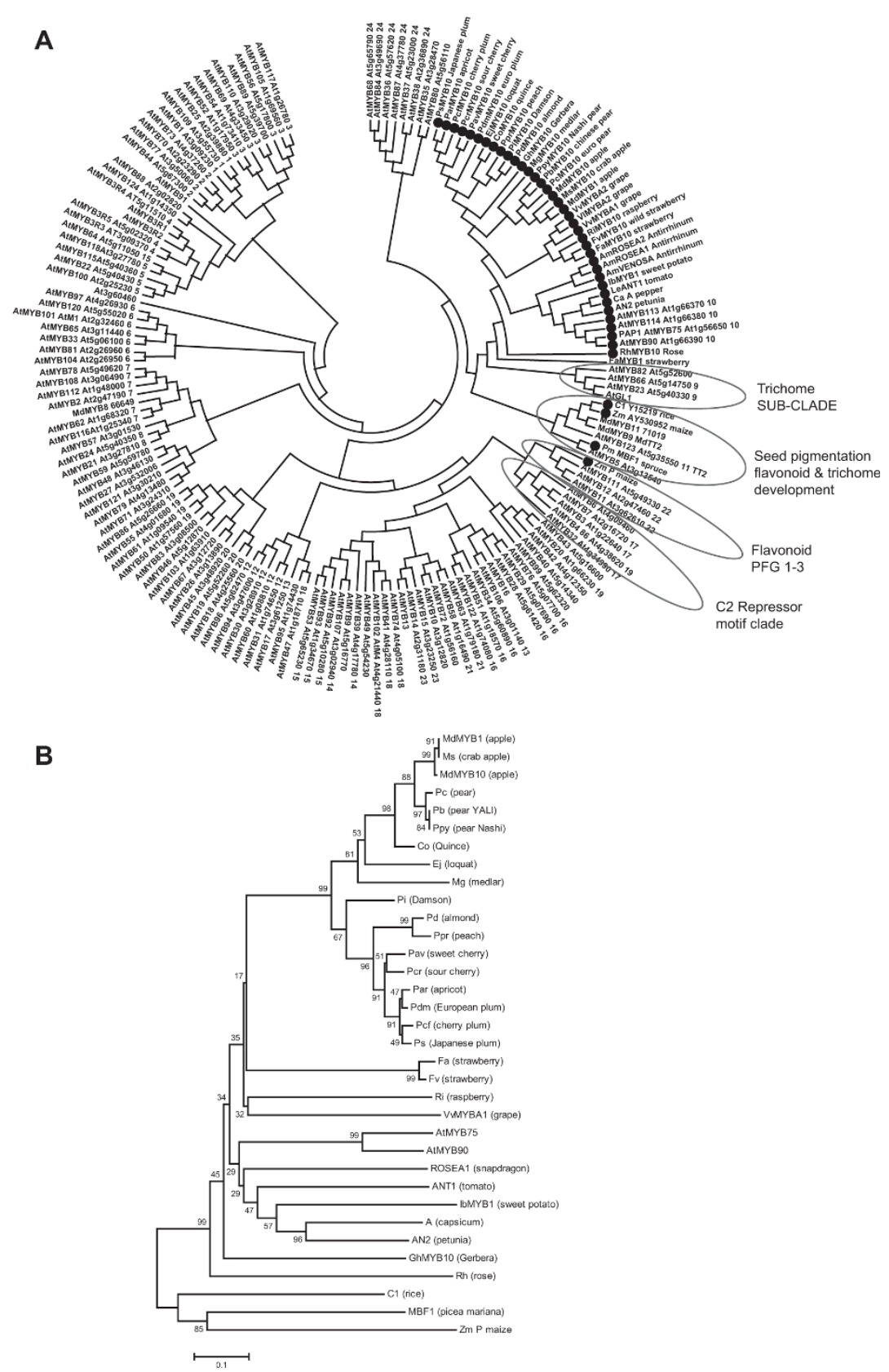

Figure 3 Phylogenetic relationships between Arabidopsis MYB transcription factors and anthocyanin-related MYBs of rosaceous and other species. Rosaceous MYB10s cluster next to PAP1 (AtMYB75) and PAP2 (AtMYB90), within the anthocyanin MYB regulator subgroup (A). A Phylogeny of MYB10 from all the major rosaceous species and known anthocyanin MYB regulators from other species (B). Sequences were aligned using Clustal W (opening $=15$, extension $=0.3$ ) in Vector NTI 9.0. Phylogenetic and molecular evolutionary analysis was conducted using MEGA version 3.1 [80] [using minimum evolution phylogeny test and 1000 bootstrap replicates].

almond and peach (Figure 2) which is within exon 3, indicating that this is not a mis-prediction of an exonintron boundary. However, this deletion did not disrupt the activity of peach MYB10 (see next section). Other anthocyanin-related MYBs are known to repress the biosynthetic pathway (e.g., FaMYB1, AtMYB3, AtMYBL2). These contain C-terminal motifs such as the ERF- associated amphiphilic repression (EAR) motif or the TLLLFR motif $[22,23]$. Such motifs were not found in any of the MYB10-like predicted proteins identified in this study.

A conserved amino acid signature ([D/E $] \mathrm{Lx}_{2}[\mathrm{R} / \mathrm{K}]$ $x_{3} L_{6} L x_{3} R$ ) (the locations indicated by the arrows in Figure 2) has been shown to be functionally important 


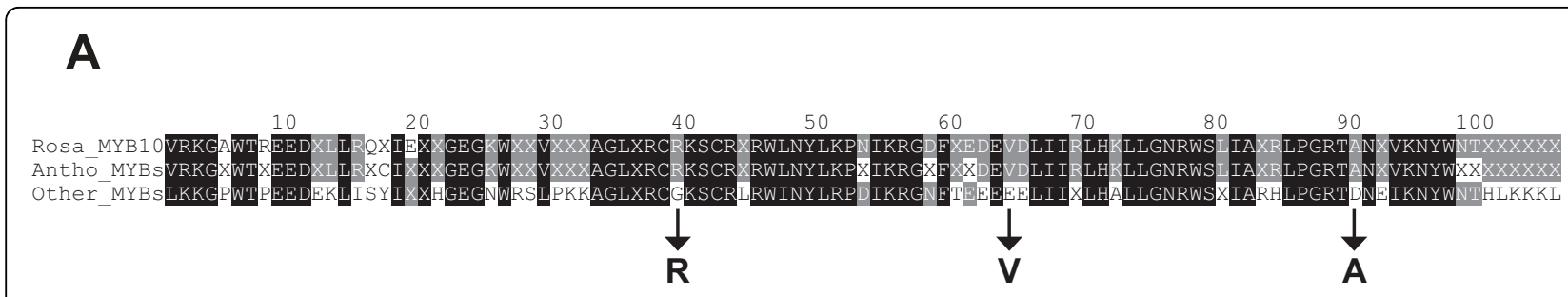

B
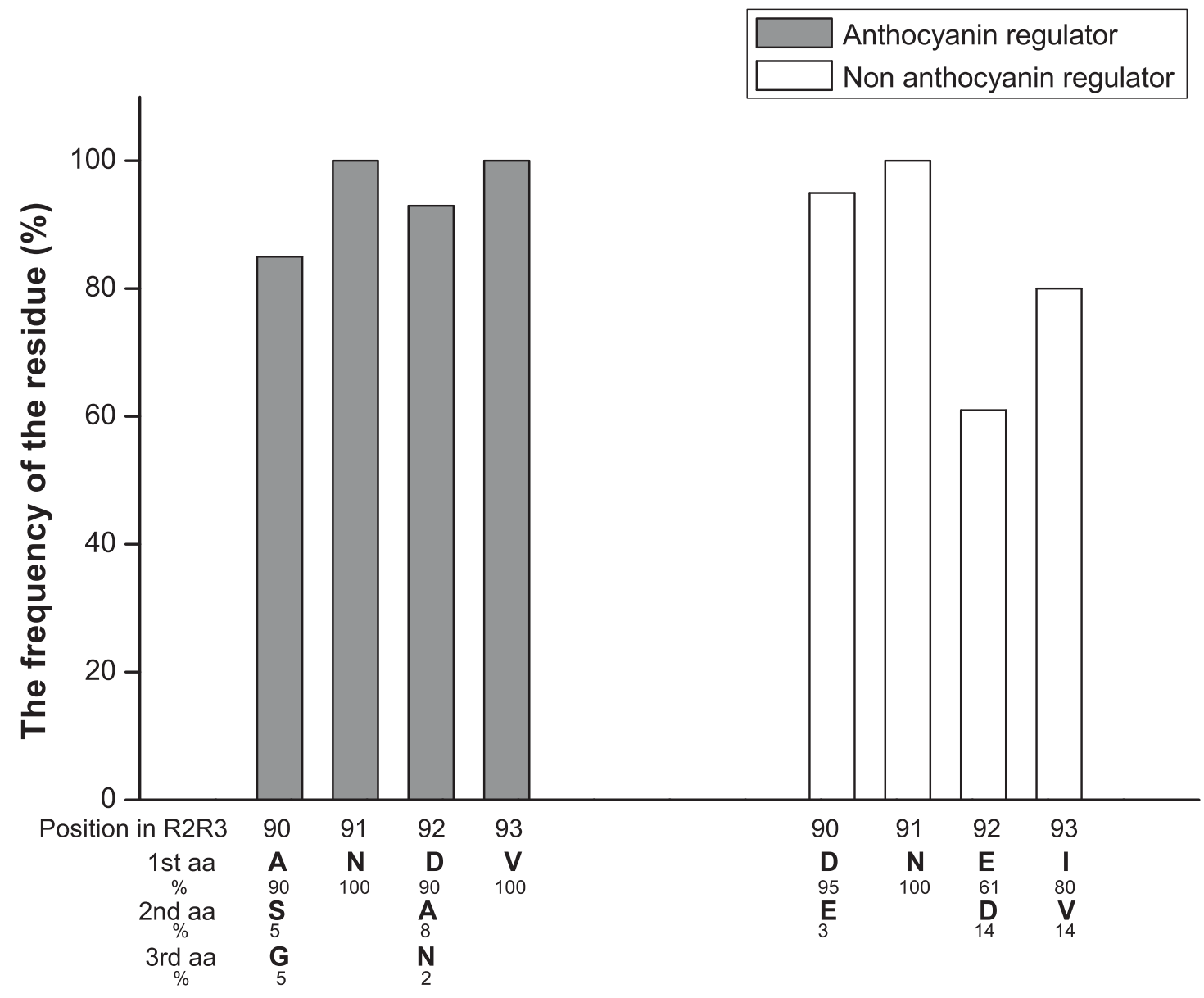

Figure 4 Analysis of R2R3 DNA binding domains of anthocyanin-promoting MYBs. Alignment (A) of three consensus amino-acid sequences from 22 rosaceous MYB10s, 38 dicot anthocyanin-promoting MYBs, and the other 134 proteins included in Figure 3A. To obtain three consensus sequences, the sequences in each of three groups were aligned using AlignX (opening $=15$, extension $=0.3$ ) in Vector NTI 9.0, and residue fraction for consensus was set to 0.9 for the alignments of 22 rosaceous MYB10s and 38 dicot anthocyanin-promoting MYBs, and 0.3 for the alignment of the other 134 proteins. (B) Frequency of residues at position 90 to 93 of the R2R3 domain covering 168 MYB TFs of Arabidopsis, rosaceous species, and other dicot sequences.

for the interaction between MYB and R/B-like bHLH proteins [44]. All rosaceous MYB sequences, as well as anthocyanin-related dicot MYBs and PmMBF1 and C1 had this signature. However, other R2R3 MYB TFs also have this signature (e.g., Arabidopsis MYBs TT2 [12] and AtMYBL2 [45]). Therefore, the presence of this motif is not indicative of the candidate MYB being within the anthocyanin-promoting clade, but rather suggests that these MYBs require an interacting bHLH partner.

\section{Functional assay of rosaceous MYB activity}

Transient luciferase assays in the tobacco species Nicotiana benthamiana have been used to assay MYB activity against the Arabidopsis DFR-promoter (dihydro flavanoid reductase; At5g42800, [24,46]). Full length cDNAs of apple $(M Y B 10)$, wild and cultivated strawberry ( $\mathrm{Fv}$ and $\mathrm{Fa} M Y B 10)$, rose ( $\mathrm{Rh} M Y B 10)$ and raspberry (RiMYB10), and genomic DNA of pear, European plum, cherry-plum, cherry, apricot, and peach (PcMYB10, 
PdmMYB10, PcfMYB10, PavMYB10, ParMYB10, and $\operatorname{Ppr} M Y B 10$, respectively) were cloned into the transient expression vector pGreen II $002462 \mathrm{~K}$ [46] and transfected into Agrobacterium. These TFs were then coinfected into $N$. benthamiana leaves with AtDFR-LUC in a second Agrobacterium strain, with or without a bHLH co-factor in a third Agrobacterium strain. Transactivation was assayed 3 days later as a change in LUC/ REN ratio.

As shown in Figure 5A, all 11 MYB10s induced the DFR promoter, but only in the presence of a bHLH partner (either AtbHLH2, AtbHLH42, MdbHLH3 or MdbHLH33). In all cases, MYB10 activity increased to the greatest extent with At $b H L H 2$ or AtbHLH42. Apple MYB10 performed well with apple bHLHs. With cherryplum, European plum, apricot, and raspberry, the induction by the MYB and bHLH was highly efficient, out-performing 35S:Renilla by at least 3-fold. Some of the MYB10 TFs (e.g., strawberry, pear, peach and rose) performed poorly with MdbHLH3. The poorest activator of AtDFR-LUC, PcMYB10, could enhance transcription of the LUC reporter to 0.45 of 35S:Renilla with AtbHLH2 as a partner. MYB8, an apple R2R3 MYB from an unrelated clade, was included as a negative control. The induction of AtDFR-LUC by $\mathrm{Md} M Y B 8$, with AtbHLH2, AtbHLH42, MdbHLH3 or MdbHLH33, was significantly lower than all rosaceous MYB10s.

As previously reported [24] a patch of foliar anthocyanin production can be induced in Nicotiana tabacum leaves by co-expression of $\mathrm{Md} M Y B 10$ with $\mathrm{Md} b H L H 3$. Induction of anthocyanin biosynthesis in transient assays by rosaceous MYB10s was tested and found to be dependent on the co-expression of the bHLH proteins from Arabidopsis or apple. Patches of anthocyanin were most apparent with $\operatorname{Pdm} M Y B 10$ and PprMYB10 when AtbHLH2 was included as a partner (Figure $5 \mathrm{~B}$ ).

\section{Expression of rosaceous MYB10 TFs correlate with anthocyanin biosynthesis}

Expression of sweet cherry PavMYB10 gene transcript was examined using qPCR analysis during fruit development in two cherry cultivars, 'Rainier' and 'Stella'. These two cultivars differ in the level of anthocyanin that accumulates in mature fruit (Figure 6A). At maturity, 'Rainier' appears pink as anthocyanin accumulates in the fruit skin, while 'Stella' is a deep red variety with high skin and flesh anthocyanin at maturity. Transcript of $\mathrm{PavMYB10}$ accumulated in the fruit tissues of both cultivars. However, the level of expression is much higher in the fruit of 'Stella' compared with 'Rainier' at the latter two stages of fruit development (Figure 6B). Expression of cherry CHS, an early step in the anthocyanin biosynthesis pathway, and cherry $L D O X$, a later step, showed up-regulation correlated with cherry colour (Figure 6B).
Expression of the strawberry genes, $F v M Y B 10$ and FaMYB10, was examined by qPCR analysis during a fruit development series of wild diploid strawberry (Fragaria vesca) and cultivated octaploid strawberry (Fragaria $\times$ ananassa; Figure 7). Expression of an R2R3 MYB repressor of anthocyanin biosynthesis, FaMYB1 [19] was also examined in the same fruit series. There was a large increase in the relative transcript levels of the MYB10 transcription factor in the fruit tissues (Figure 7A). In F. ananassa, transcript levels of FaMYB10 were detectable but low until fruit were full size (Figure $7 \mathrm{~B}$ ). Upon ripening and colour change, there was an almost 40,000-fold increase in relative transcript level. FaMYB1 showed an expression pattern similar to that published, with the highest transcription level at the ripe fruit stage [19] while FvMYB1 expression showed little change. Expression levels of FvMYB10 in $F$. vesca also correlate with colour change. F. vesca has an earlier colour change, which occurs only in the skin (Figure 7C). For the mature fruit, the increase of FaMYB10 is almost 10 times more than that of $F v M Y B 10$. This may be due to cultivated strawberry fruit having anthocyanin throughout fruit flesh and skin while the wild strawberry accumulates anthocyanin only in the outer cell layers of the mature fruit.

Under stressful conditions (high light), the petals of F. vesca flowers became pigmented (Figure 7D). While FvMYB1 showed little change in these petals, the transcript of $F v M Y B 10$ from this tissue showed a large increase in accumulation compared with the petals that were not exposed to high light and were unpigmented. This is further evidence that MYB10 in strawberry is involved in regulating anthocyanin accumulation.

\section{Transformation of MYB10 into the crop of origin results in elevation of anthocyanin biosynthesis}

It has been recently reported that transformation of 'Royal Gala' apple with 35S:MdMYB10 results in plants ectopically accumulating anthocyanins [24,42]. In contrast, when 35S:FaMYB10 was transformed into $F$. ananassa, (using an adapted protocol [47]), callus and plantlets were not highly pigmented. When these plants were grown under short day conditions ( $8 \mathrm{~h}$ day, $16 \mathrm{~h}$ night) to encourage flowering and then transferred to long days, 35S:FaMYB10 plants had elevated foliar anthocyanins (Figure 8A), and red roots (Figure $8 \mathrm{~B}$ ). All of the 35S:FaMYB10 transgenic lines had flowers which showed distinctive red stigmas (Figure $8 \mathrm{C}$ ). Transgenic fruit from these lines had immature fruits with red seeds, and mature fruits with approximately 50\% more anthocyanin. These fruit had the same compound profile as wild-type fruit (cyanidin-glucoside: pelargonidinglucoside: pelargonidin rutinoside at approximately 1:50:5 as measured with HPLC; Figure 8E, Additional 


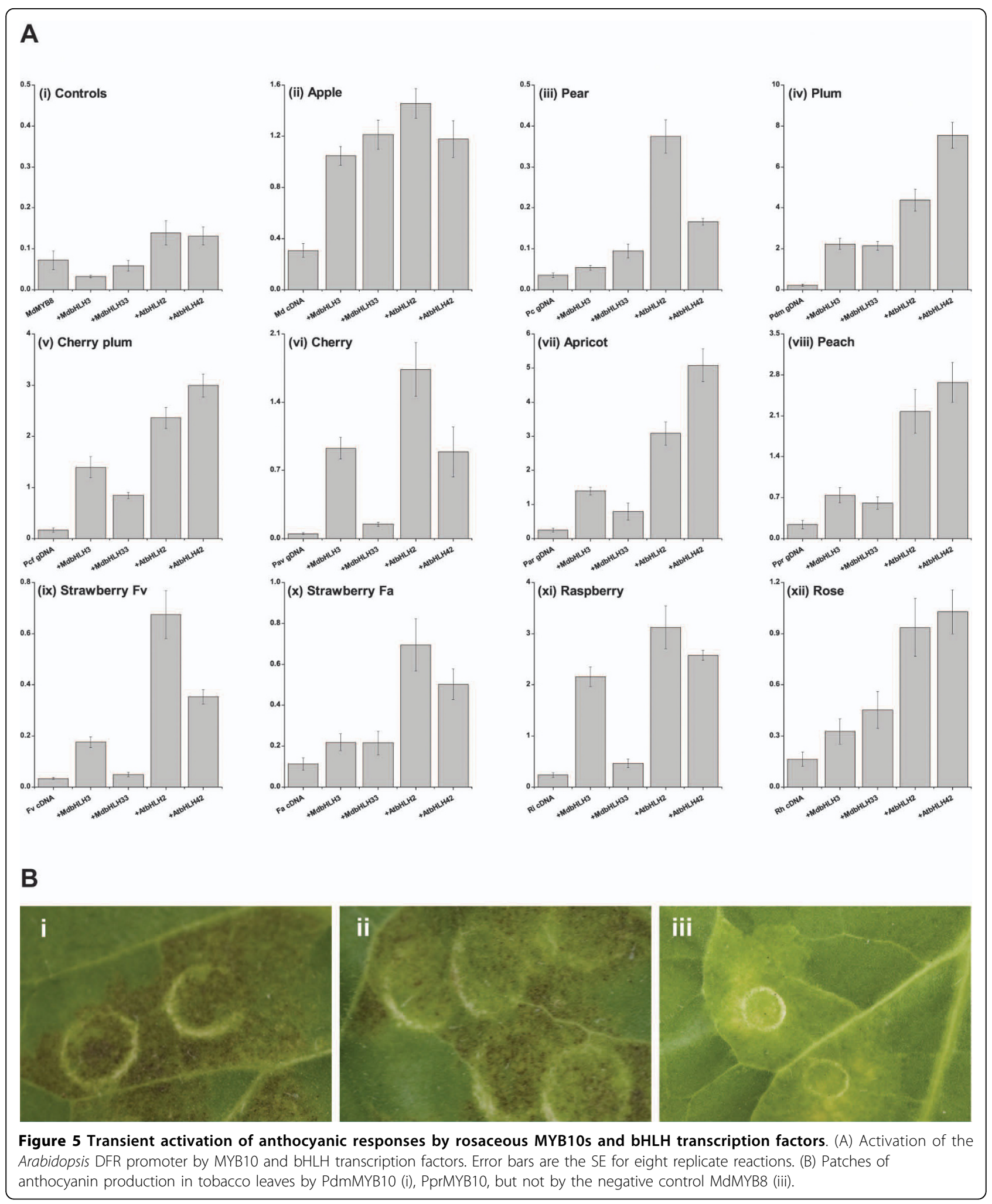




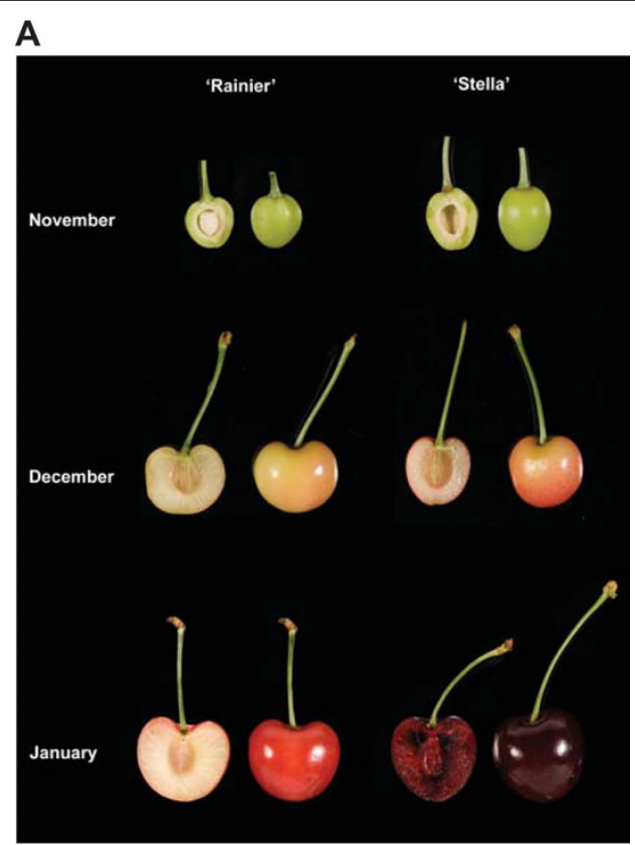

B

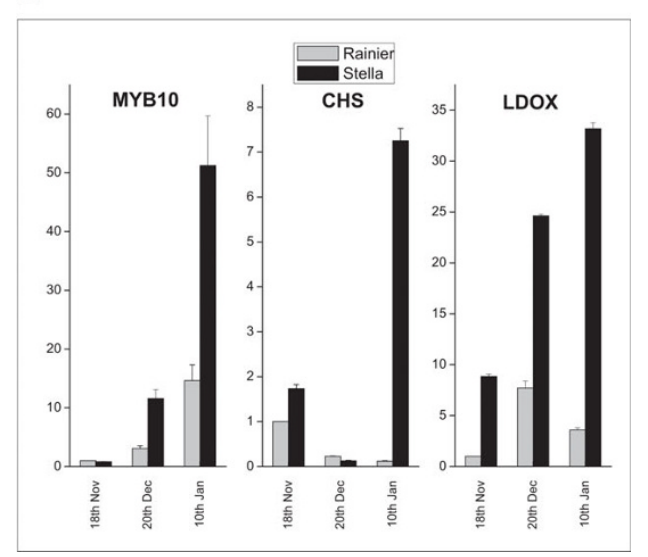

Figure 6 Normalized quantitative Real-Time of the expression of cherry PavMYB10. Expression of PavMYB10 $n$ the developmental series from sweet cherry 'Rainier' and 'Stella'. (A) Fruit sampled and (B) GPCR expression of PavMYB10, CHS and LDOX using 'Rainier' green fruitlet as a calibrator. Error bars are the SE for three replicate reactions.

File 3). Transcript analysis of 35S:FaMYB10 lines confirmed an elevation of FaMYB10 transcript level in both the fruit and leaf tissue (Additional File 3). No elevation in FaMYB1 transcript level was observed in transgenic tissue versus wild-type.

\section{Discussion}

\section{The plant MYB family}

The MYB TF superfamily illustrates how a relatively small family in animal genomes (3 members of this TF type in the human genome by BLAST match) controlling cell division and differentiation has become the most abundant TF group in plants [48] with diverse functions in hormone response [49], growth [50], epidermal cell fate and formation of trichomes [51], stomatal movements and development [52]; [53], seed development [54], response to drought [55] and cold $[56,57]$, pathogen-response [58,59], light-sensing responses [60,61], sugar-related responses [62], modulation of secondary metabolites such as glucosinolates $[63,64]$ and phenylpropanoids [65]. MYB proteins have a conserved N-terminal DNA binding domain of 100-160 residues, depending on the number of $\mathrm{R}$ repeats, with each repeat containing a helix-helix-turn-helix structure. Within this N-terminal region are key residues important for trans-activation efficiency [66], residues that regulate and specify DNA binding [14], and interactions with bHLHs [67]. We have identified in this study several residues shared by anthocyanin-promoting MYBs, from diverse species, that may be important in their function (Figure 4).

Consensus motifs in the C-terminus of MYBs, important for function are just beginning to be elucidated. One such example is the case of the C2 EAR motif repressor clade. AtMYB4 has the motif NLELRISLPDDV, which is essential for its repressive activity against the $\mathrm{CH} 4$ promoter [20]. This motif (pdLNLD/ ELxiG/S) is also conserved in a number of R2R3 MYB proteins belonging to subgroup 4 which includes AtMYB4, AtMYB6, AtMYB7 and AtMYB32, and Antirrhinum AmMYB308 and AmMYB330, which have very similar effects to AtMYB4 when over-expressed in tobacco [21]. FaMYB1 also has such a motif [19]. In anthocyanin-promoting MYBs, the motif KPRPR[S/T]F was identified [65]. By analysing more MYBs of this clade we found variation in this $\mathrm{C}$-terminal motif (Figure 2), but enough conservation to suggest it could be used as an identifier.

\section{MYBs involved in regulation of phenylpropanoid levels}

The phenylpropanoids include flavonoids, anthocyanins, and proanthocyanidins. The accumulation of these compounds in plants and plant organs is central to such quality parameters as colour, human health, bitterness and astringency, as well as plant response to biotic and abiotic stress. R2R3 MYBs are responsible for controlling different aspects of the phenylpropanoid pathway in a wide range of different plant species. These include flavonol-specific MYBs [65], proanthocyanidin-specific MYBs [68], inhibitors of branch points [69] and R2R3 MYBs specifically controlling the anthocyanin biosynthetic pathway genes as well as anthocyanin conjugation, transport into the vacuole [70], and acidification of this compartment to affect fruit/flower/foliage colour [71]. 


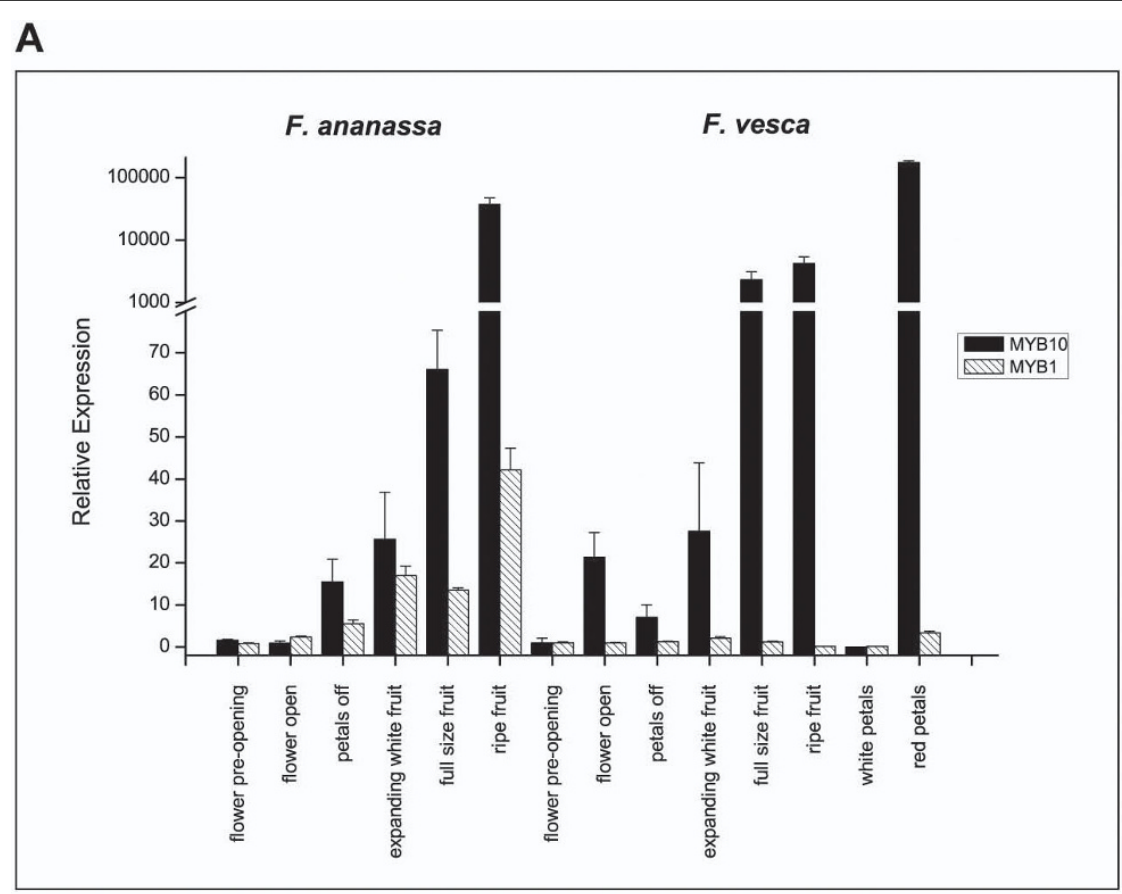

B

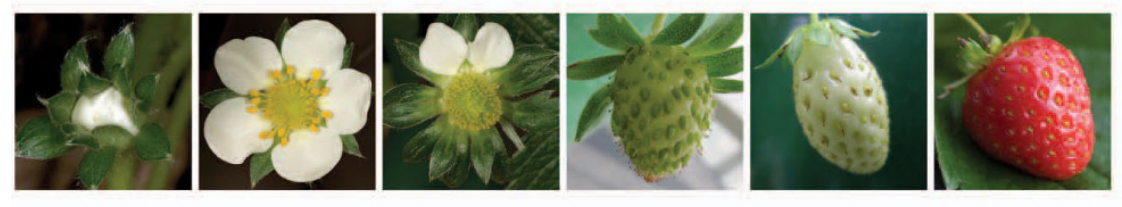

C

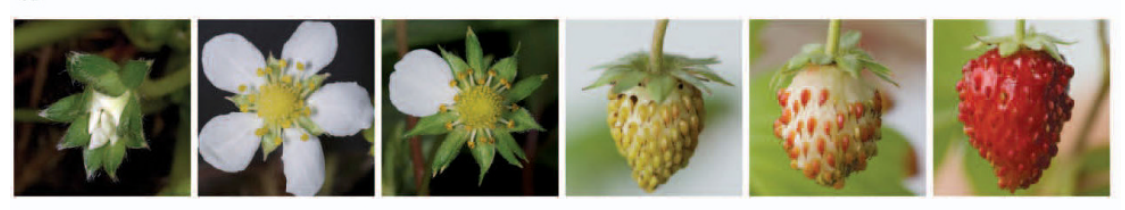

D

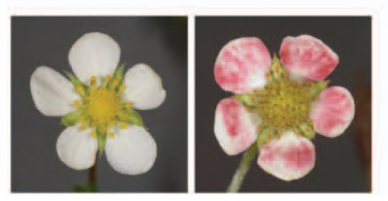

Figure 7 Normalized qPCR data of the expression of strawberry MYB10 and MYB1. QPCR expression of Fragaria MYB10 and MYB1 in a fruit developmental series from both cultivated and wild strawberry (A). Fv stage 1 was set as a calibrator. Error bars are the SE for three replicate reactions. (B) Six developmental stages of cultivated strawberry. (C) Six developmental stages of wild strawberry. (D) White and red petals of wild strawberry.

In Arabidopsis, one of the R2R3 anthocyanin-related clades is made up of AtMYB75 (PAP1, At1g56650; [18], AtMYB90 (AtPAP2, At1g66390), AtMYB113 (At1g66370), and AtMYB114 (At1g66380). As three of these MYBs occur in order on chromosome 1, they may have arisen by tandem duplications of AtMYB75. Overexpression of PAP1 [70], AtMYB113 and AtMYB114 [26] all result in elevated anthocyanin levels. By examining homologues of PAP1 in other species, we have identified residues that predict MYBs involved in anthocyanin regulation. This anthocyanin-promoting clade is apparently absent in the rice genome and other monocots and gymnosperms, suggesting recent divergence of these MYBs.

In apple, three MYB genes have been independently isolated, all of which control anthocyanin levels and 
A

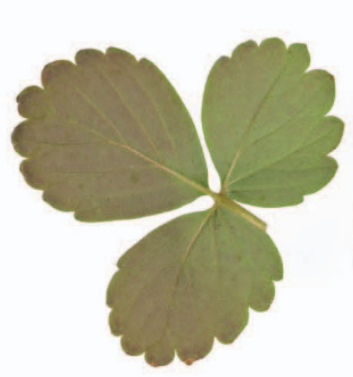

B

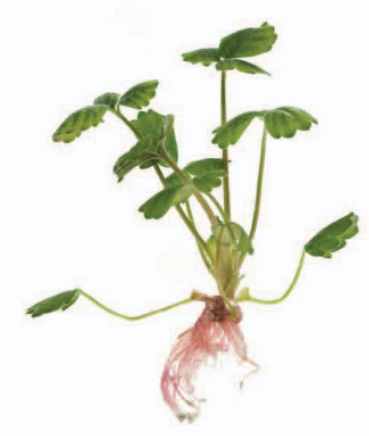

C

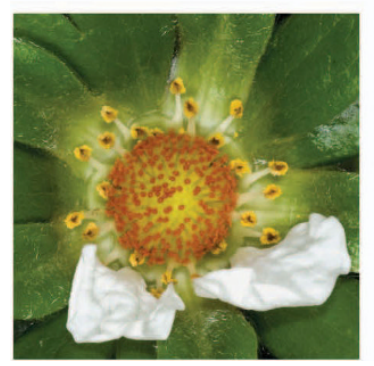

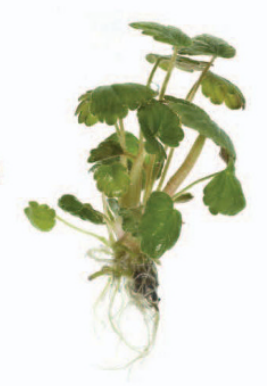

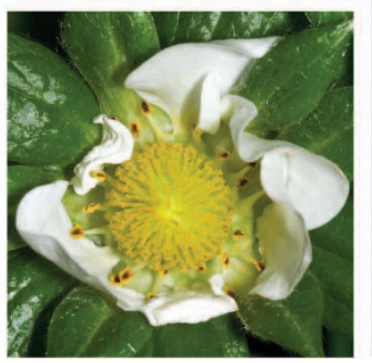

D
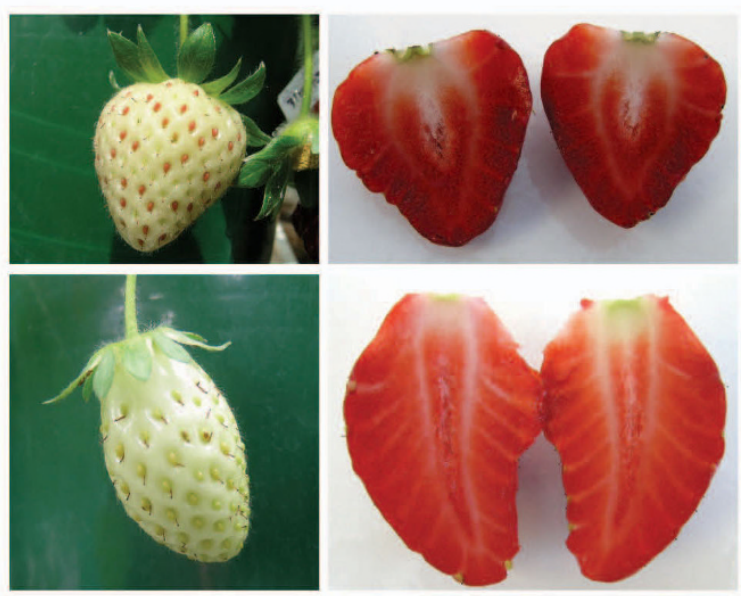

E

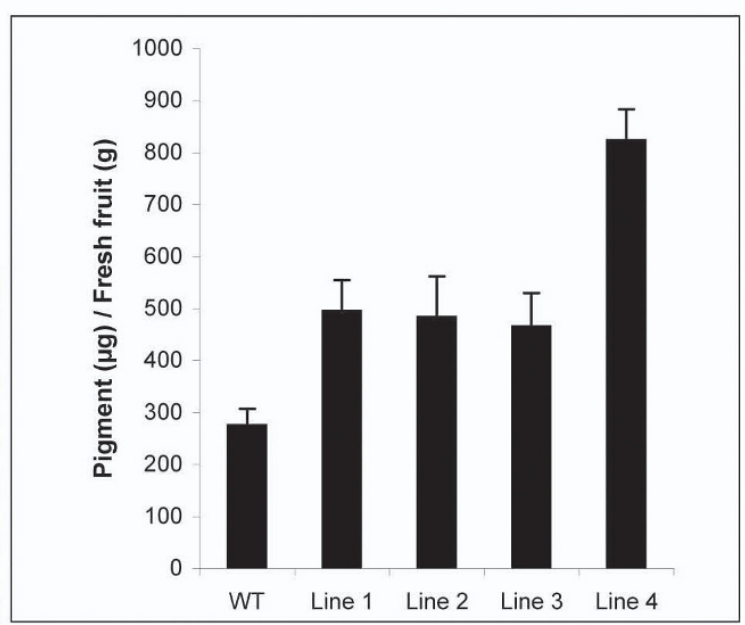

Figure 8 Transformation of strawberry with 35S:FaMYB10 elevates anthocyanin synthesis. Cultivated strawberry was transformed with 35S: FaMYB10. Visible reddening was seen in leaves ( $\mathrm{A} ; \mathrm{WT}$ on right) and roots $(\mathrm{B} ; \mathrm{WT}$ on right), and in flowers ( $\mathrm{C} ; \mathrm{WT}$ on right). Fruits showed red seeds and elevated anthocyanin (D; transgenic top photos, WT below). Extracted pigment was anthocyanin and increased in all lines (E). Error bars are the SE for four replicate extracts per line.

show a very high degree of sequence similarity; $M Y B 10$, $M Y B 1$ and $M Y B A$. It has been suggested that MYB1 and $M Y B A$ are alleles arising from the different varieties from which they were cloned [38]. The MYB10 sequence is more diverse. It is difficult, from sequence analysis alone, to distinguish between recently duplicated gene paralogues and allelic variation between different varieties. By designing PCR primers to a region of sequence common to both MYB10 and MYB1, we were able to distinguish between the $M Y B 10$ allele from 'Red Field', which produces a 1000 -bp amplification product and other MYB10 alleles (from 'Royal Gala' amongst others) and the MYB1 alleles from Pacific Rose ${ }^{\mathrm{m}}$ and 'Royal Gala' that produce a 900-bp fragment. If $M Y B 1$ and $M Y B 10$ were paralogues then, in the varieties that only amplified a 900-bp fragment, this fragment would be the product of four alleles (i.e. two from each of the parologous genes). However, if MYB10 and MYB1 are allelic, the 900-bp fragment would only be produced by two alleles, one from each of the $M Y B 10 / M Y B 1$ alleles of the parents. Accordingly, in red-fleshed varieties which are heterozygous for the promoter polymorphism, such as 'Robert's Crab', one of the MYB10 alleles produces a 1000-bp fragment, and the other allele a 900-bp fragment. In homozygous Malus sieversii 01P22 there is only the 1000-bp fragment. In addition to this, if $M Y B 1$ was a paralogue, a further two 900-bp products would be contributed from the MYB1 alleles. As we do not see DNA fluorescence consistent with a 1:3 amplification of the 1000 - and 900-bp fragments, we propose that MYB10 
and $M Y B 1 / M Y B A$ are alleles. The future availability of whole genome sequence for apple will aid a conclusion on the allelic structure of this gene.

\section{Identification of anthocyanin-promoting MYB10 genes in rosaceous crops}

Using degenerate PCR based on the MYB10 sequence, we have been able to isolate 20 MYB10-like genes from a range of rosaceous species. Analysis of the genomic DNA of these species predicts that all the genes contain two introns in positions consistent with the intron location of other MYB genes [72]. Almost all of the variation in gene size is due to alterations in the predicted length of intron 2 (Table 1). Aligning intron 2 of Malus MYB10 (crab and domesticated apple; $\sim 3000 \mathrm{bp}$ ) and Pyrus MYB10 (European and Asian pears; 500 bp) revealed a high degree of similarity except within a region of intron 2 where there appears to have been a 2500-bp insertion. This does not contain inverted repeats or sequence signatures that are indicative of mobile genetic elements such as transposons or helitrons [73]. This insertion could be the result of a local genome rearrangement that took place after the speciation of apple and pear, but before the divergence of apple and crab apples.

Botanical classification of the Rosaceae has recently been undertaken using 88 species analysed for a combination of phenotypic and molecular marker [74]. Using the nuclear encoded genes, polygalacturonase inhibitor protein (PGIP) and polyphenol oxidase (PPO), a weak or conflicting phylogenic resolution was produced. We have complemented this analysis, on a smaller dataset, by adding additional information relating to a single copy nuclear gene, where orthology has been inferred by both sequence and functional characterisation. The phylogenic placements are in broad agreement with the Pyrinae subtribe and Amygdaloideae tribe described [74].

\section{Transient activation of the anthocyanin pathway by rosaceous MYB10s requires a bHLH}

Within the R2R3 domain of all 20 MYB10s there were several key motifs suggesting an association with a bHLH partner. Several anthocyanin-promoting MYBs have been assayed in heterologous systems; for example, tobacco [24,39], Arabidopsis [39] or Antirrhinum petal cells [34] and this trans-activation is often enhanced by the co-infiltration of an appropriate $b H L H$ gene $[24,37,42]$. We used transient assay of rosaceous MYB genes, with the DFR promoter from Arabidopsis and bHLH genes from either apple or Arabidopsis. All of the isolated MYB TFs were able to trans-activate the DFR promoter in the presence of at least one of the four bHLHs tested. Only the apple MYB10 gene responded equally to either apple or Arabidopsis bHLH genes. This may indicate a degree of specificity that exists for the apple bHLH gene and its association with apple MYB gene and target promoter. However, the degree of transactivation, and interaction with bHLH partners, varies greatly amongst the rosaceous MYBs genes tested (Figure 5). In particular, plum and apricot showed transactivation values in excess of five times that of the 35Spromoter. Such high trans-activation potential may be due to more effective interaction of plum and cherry MYBs with tobacco transcription factors endogenous within the transient assay, or could point to an enhanced ability of these MYBs to promote high levels of anthocyanin. Further analysis of these MYB TFs in homologous systems is required, and techniques such as yeast-2-hybrid used to probe which protein residues are responsible for strong or weak interactions.

\section{MYB10 expression is strongly associated with anthocyanin production in fruits}

During fruit development, in both strawberry and cherry, the transcript level of MYB10 was up-regulated. A correlation between transcript and anthocyanin production has already been reported in apple [24,38,39]. In a cherry cultivar which has lower anthocyanin levels at maturity the expression of MYB10 transcript was lower than in a dark-fruited cultivar. It remains for these genes to be mapped in crops segregating for different pigmentation levels. However, for apple, MYB10/MYB1/ $M Y B A$ is the major gene in a crossed population segregating for red flesh [75] and red skin [38].

Transformation of strawberry with FaMYB10 resulted in plants with elevated root, foliar and fruit anthocyanin levels (Figure 8). These levels were not as high as previously reported in 35S:MdMYB10 apple transformants [24], due perhaps to other partners in the MYB/bHLH/ WD40 complex. It has been shown recently that tomato fruits, with elevated anthocyanins due to over-expression of MYB and bHLH members of the MBW complex, are responsible for promoting human health attributes $[6,76]$.

\section{Conclusions}

The Rosaceae family-wide characterisation of MYBs provides insight into the evolution of this TF and has implications for the understanding of temporal-spatial colour change. Our identification of this set of MYBs will aid development of new rosaceous fruit and flowers by allowing the testing of co-segregation of MYB alleles with pigment phenotypes in Rosaceae, which are both common and highly sought after (e.g., rose, plum, cherry, peach). If these candidate genes do segregate for anthocyanin levels, gene-based marker-assisted selection or even cisgenics could be used in breeding programmes. This approach has worked for apple [75] and 
there is preliminary evidence that PavMYB10 co-locates with a QTL for fruit and flesh colour in cherry (A. Iezzoni and J. Bushakra, pers. comm.) and PprMYB10 colocates with anther colour segregating in the peach reference map (J. Bushakra and P. Arus, pers. comm.). This group of transcription factors therefore becomes useful as a breeding and biotechnological tool.

\section{Methods}

\section{Isolation of rosaceous transcription factors}

Fruit and leaf samples of 20 rosaceous species were collected as follows: crab apple (Malus sylvestris), sweet cherry (Prunus avium), sour cherry (Prunus cerasus), almond (Prunus dulcis), peach (Prunus persica), Japanese plum (Prunus salicina) and rose (Rosa hybrida) from Auckland Botanic Gardens (Auckland, New Zealand); quince (Cydonia oblonga), loquat (Eriobotrya japonica), medlar (Mespilus germanica), pear (Pyrus communis), apricot (Prunus armeniaca), Damson (Prunus insititia), European plum (Prunus domestics), cherry-plum (Prunus cerasifera) from local gardens (Auckland, New Zealand); strawberry (Fragaria $\times$ ananassa and Fragaria vesca) from Plant \& Food Research greenhouse (Auckland, New Zealand); red raspberry 'Latham' (Rubus idaeus), pear 'Nashi' (Pyrus pyrifolia), and Chinese pear 'Yali' (Pyrus $\times$ bretschneideri) from various Plant \& Food Research orchards.

Messenger RNA (mRNA) was isolated using an adapted method [77] from pigmented fruit or flower tissue, and genomic DNA (gDNA) was isolated (DNeasy Plant Mini Kit, Qiagen) from young leaves or flower buds. MYB10s of pear (Pyrus communis) and cherryplum (Prunus cerasifera) were successfully obtained by applying various primers based on $M d M Y B 10$ in cDNA or gDNA PCR amplification. With more primers based on PcMYB10 and PcfMYB10, MYB10s from two subfamilies, Maloideae and Amygdaloideae, were completed by overlapping PCR fragments. For the subfamily Rosoideae, which includes Fragaria, Rubus and Rosa, degenerate primers, designed to the consensus DNA sequence of R2R3 binding domain were used in 5' and 3' GeneRace (GeneRacer Kit, Invitrogen). The complete sequence for $M Y B 10$ was compiled from overlapping fragments and full length clones were isolated using gene-specific primers designed to the 5' and 3' UTR regions. Phylogenic trees were generated using MEGA 3.1, a minimum evolution phylogeny test and 1000 bootstrap replicates.

\section{Dual luciferase assay of transiently transformed Nicotiana benthamiana leaves}

The promoter of Arabidopsis DFR (TT3, AT5g42800) was isolated from genomic Arabidopsis DNA and cloned into pGreenII 0800-LUC vector [46]. MYB10 cDNA or gDNA full length sequence from 10 selected rosaceous species was cloned into pGreen II 62-SK 0029 binary vectors [46].

Nicotiana benthamiana plants were grown under glasshouse conditions until about $5 \mathrm{~cm}$ in height. Approximately $150 \mu \mathrm{l}$ of Agrobacterium culture was infiltrated at four points into a young leaf. Three days after inoculation, 3-mm leaf discs (4 technical replicates from each plant) were cut with a hole-puncher, placed into wells of a 96-well-plate containing $50 \mu \mathrm{l}$ of PBS (phosphate buffered saline) in each well, and gently crushed with the hole-puncher. The measurement and analysis was carried out using an Orion Microplate Luminometer (Berthold Detection System), using the manufacturer's recommended conditions.

\section{PCR expression analysis}

Strawberry fruits from Fragaria $\times$ ananassa and Fragaria vesca were collected at six time points during fruit development: stage 1, pre-opened bud; stage 2, fully open flower; stage 3 , petal drop; stage 4 , expanding fruitlet; stage 5, expanded fruit; stage 6 , red-ripe fruit, from plants grown under glasshouse conditions, using natural light with daylight extension to $16 \mathrm{~h}$. In one instance, Fragaria vesca was grown under constant lighting, inducing red pigmented petals. RNA was isolated [77] from fruit (six samples from the same plant, skin and cortex combined), and red and white petals. First strand cDNA synthesis was carried out by using oligo dT according to the manufacturer's instructions (SuperScript III, Invitrogen). As the identity between cDNA sequences of Fragaria $\times$ ananassa and Fragaria vesca is as high as $95 \%$, a set of qPCR primers was designed for both species using Vector NTI to a stringent set of criteria, enabling application under universal reaction conditions.

To eliminate gDNA contamination, both forward and reverse primers were designed to span an intron/exon boundary. The strawberry actin primers were based on the actin sequence of Fragaria $\times$ ananassa (Genebank number AB116565). The reverse primer of actin was also designed to span an intron.

Sweet cherry (Prunus avium) 'Stella' and 'Rainier' were collected at three time points during fruit development: stage 1, green fruitlet; stage 2, expanding fruit; stage 3, mature fruit, from a Plant \& Food Research orchard (Clyde, New Zealand). Actin primers were based on the actin sequence of closely related sour cherry Prunus cerasus (Genebank number EE488162). The method of RNA extraction and the principles of primer design were the same as strawberry.

Quantitative real time PCR (qPCR) DNA amplification and analysis was carried out using the LightCycler System (Roche LightCycler 1.5, Roche), with LightCycler software version 4. The LightCycler FastStart SYBR Green Master 
Mix (Roche) was used, and the $10 \mu \mathrm{l}$ of total reaction volume applied in all the reactions following the manufacturer's method. qPCR conditions were $5 \mathrm{~min}$ at $95^{\circ} \mathrm{C}$, followed by 40 cycles of $5 \mathrm{~s}$ at $95^{\circ} \mathrm{C}, 5 \mathrm{~s}$ at $60^{\circ} \mathrm{C}$, and $10 \mathrm{~s}$ at $72^{\circ} \mathrm{C}$, followed by $65^{\circ} \mathrm{C}$ to $95^{\circ} \mathrm{C}$ melting curve detection. The qPCR efficiency of each gene was obtained by analysing the standard curve of a cDNA serial dilution of that gene. The expression was normalized to Fragaria $\times$ ananassa actin and Prunus cerasus actin with Fragaria vesca stage 1 flower bud and Prunus avium 'Rainier' stage 1 fruitlet acting as calibrator with a nominal value of 1 . Actin was selected as a reference gene because of its consistent transcript level throughout fruits and leaves. To confirm the amplification of the expected DNA sequence, qPCR amplicons were sequenced.

Endpoint PCR analysis used in the apple MYB allele study was carried out using Platinum Taq (Invitrogen). Reaction conditions were $95^{\circ} \mathrm{C}, 5 \mathrm{~min}$ followed by 35 cycles of $30 \mathrm{~s}$ at $95^{\circ} \mathrm{C}, 30 \mathrm{~s}$ at $55^{\circ} \mathrm{C}$, and $60 \mathrm{~s}$ at $72^{\circ} \mathrm{C}$. PCR products were separated on $1 \%$ agarose gels and stained with ethidium bromide. Primer sequences are listed in Additional File 4.

\section{Growth of Strawberry plants and Generation of 35S: FaMYB10 Fragaria $\times$ ananassa plants}

Strawberry plants of Fragaria $\times$ ananassa and Fragaria vesca were grown under controlled conditions $\left(23^{\circ} \mathrm{C}\right.$ day, $15^{\circ} \mathrm{C}$ night) in a short day room $(8 \mathrm{~h}$ day, $16 \mathrm{~h}$ night) for 3 months, then plants were moved to long day conditions $\left(16 \mathrm{~h}\right.$ day, $8 \mathrm{~h}$ night, $25^{\circ} \mathrm{C}$ day, $15^{\circ} \mathrm{C}$ night) to encourage flowering.

Surface sterilized seeds were germinated on 1/2 MS basal salt and vitamins (Duchefa) $+3 \%$ sucrose $+0.7 \%$ agar (Germantown) ( $\mathrm{pH}$ 5.7) medium. Seedlings were sub-cultured onto fresh medium every four weeks. Young leaves excised from in vitro grown shoots were cut into $\sim 1 \times 2 \mathrm{~mm}$ leaf strips. Transformation was via an adapted protocol (from [47] with Agrobacterium tumefaciens strain EHA105 [78], harbouring the binary plasmid pGreen II 0029 62-sk [79] containing the NOS/ NPT II for kanamycin resistance, and a CaMV 35s promoter-driven full length FaMYB10 cDNA.

\section{HPLC measurement of strawberry fruits}

Two mature strawberry fruits were taken from each of three plants representing two transgenic lines and a wild-type control. The fruits were freeze-dried for at least $24 \mathrm{~h}$. The dried tissue was then pulverized, resuspended in ethanol: distilled water: formic acid (80:20:1) with the ratio of $5 \mathrm{~mL}$ solvent to $1 \mathrm{~g}$ of original fresh fruit weight, extracted at room temperature for $3 \mathrm{~h}$ in the dark, centrifuged at $3500 \mathrm{rpm}$ for $10 \mathrm{~min}$. A $1-\mathrm{ml}$ aliquot of the supernatant was analyzed for anthocyanin components by HPLC. The HPLC system consisted of a Waters Alliance Separation Module (model 2690) and a photodiode array detector (model 996) under the control of Chromeolen (Dionex, USA) software. The separation column used was a Zorbax Rapid Resolution SB-C18 $4.6 \times 150 \mathrm{~mm}$ (Agilent, USA) with a binary solvent program $(\mathrm{A}=$ formic acid/MQ water (5:95); $\mathrm{B}=$ acetonitrile) that started at $95 \%$ A $5 \%$ B at injection, changed to $80 \% \mathrm{~A} 20 \% \mathrm{~B}$ at 9 minutes; $20 \% \mathrm{~A} 80 \% \mathrm{~B}$ at 18 minutes and held for 2 minutes before returning to $95 \%$ A 5\%B ready for the next sample injection. Total flow rate was $0.8 \mathrm{~mL} / \mathrm{min}$ and sample injection volumes were $5 \mu \mathrm{L}$. Anthocyanin components were detected at 530 $\mathrm{nm}$, and peaks indentified by retention time with authentic standards, and previous reports of strawberry anthocyanins.

\section{Additional file 1: Schematic of the MYB10 gene from all the major rosaceous species. MYB10 exon and intron composition, with the size of intron 2 variation as a correlation with estimated genome size. \\ Additional file 2: Table of key amino-acid residues in R2R3 MYBs. Key amino-acid motif at position 90 to 93 in R2R3 domain of 173 MYB transcription factors of Arabidopsis, Rosaceae, and other species. \\ Additional file 3: Analysis of transgenic strawberry. QPCR of MYB10 and MYB1 and extracted anthocyanins of wild type ripe fruit and 35S- MYB10 ripe fruit. \\ Additional file 4: Primers used in this study. Table of oligonucleotide primers used in this study.}

\section{Acknowledgements}

We wish to thank Mary Petley, Eric Walton, and Jill MacLaren, of Plant \& Food Research for assistance with collection of plant material, and Jill Bushakra, David Chagné, and William Laing of Plant \& Food Research for assistance with the manuscript, and Niels Nieuwenhuizen, Tim Holmes, and Minna Pesonen for technical assistance. This research was funded by a grant from the New Zealand FRST contract "HortGenomics CO6X0207".

\section{Author details}

${ }^{1}$ The New Zealand Institute for Plant \& Food Research Ltd, (Plant and Food Research), Mt Albert Research Centre, Private Bag 92169, Auckland, New Zealand. 'Wageningen UR Plant Breeding, Postbus 386, 6700 AJ, Wageningen, The Netherlands. ${ }^{3}$ Plant and Food Research, Palmerston North 4442 , New Zealand.

\section{Authors' contributions}

$K L W, K B, K G$ and AK isolated and cloned the rosaceous MYBs. AK and RVE designed and performed allele specific apple gene amplification. SK cloned bHLH transcription factors. KLW transformed strawberry, and TKM analyzed the resulting plants. KLW, RPH, and ACA conceived the study, participated in the design, and drafted and edited the manuscript. All authors read and approved the final manuscript.

Received: 8 November 2009 Accepted: 21 March 2010 Published: 21 March 2010

\section{References}

1. Tanaka Y, Sasaki N, Ohmiya A: Biosynthesis of plant pigments: anthocyanins, betalains and carotenoids. Plant J 2008, 54(4):733-749.

2. Feild TS, Lee DW, Holbrook NM: Why leaves turn red in autumn. The role of anthocyanins in senescing leaves of red-osier dogwood. Plant Physiol 2001, 127(2):566-574. 
3. Winkel-Shirley B: Flavonoid biosynthesis. A colorful model for genetics, biochemistry, cell biology, and biotechnology. Plant Physiol 2001, 126(2):485-493.

4. Regan BC, Julliot C, Simmen B, Vienot F, Charles-Dominique P, Mollon JD: Fruits, foliage and the evolution of primate colour vision. Philos Trans $R$ Soc Lond B Biol Sci 2001, 356(1407):229-283.

5. Schaefer HM, Schaefer $V$, Levey DJ: How plant-animal interactions signal new insights in communication. Trends in Ecology \& Evolution 2004, 19(11):577.

6. Butelli E, Titta L, Giorgio M, Mock HP, Matros A, Peterek S, Schijlen EG, Hall RD, Bovy AG, Luo J, Martin C: Enrichment of tomato fruit with healthpromoting anthocyanins by expression of select transcription factors. Nat Biotechnol 2008, 26(11):1301-1308.

7. Boyer J, Liu RH: Apple phytochemicals and their health benefits. Nutrition Journal 2004, 3:5.

8. Gallus S, Talamini R, Giacosa A, Montella M, Ramazzotti V, Franceschi S, Negri E, La Vecchia C: Does an apple a day keep the oncologist away? Ann Oncol 2005, 16(11):1841-1844.

9. Liu RH, Liu J, Chen B: Apples prevent mammary tumors in rats. J Agric Food Chem 2005, 53(6):2341-2343.

10. Nijveldt RJ, van Nood E, van Hoorn DE, Boelens PG, van Norren K, van Leeuwen PA: Flavonoids: a review of probable mechanisms of action and potential applications. Am J Clin Nutr 2001, 74(4):418-425.

11. Rasmussen SE, Frederiksen H, Struntze Krogholm K, Poulsen L: Dietary proanthocyanidins: occurrence, dietary intake, bioavailability, and protection against cardiovascular disease. Mol Nutr Food Res 2005, 49(2):159-174.

12. Baudry A, Heim MA, Dubreucq B, Caboche M, Weisshaar B, Lepiniec L: TT2, $\Pi \pi 8$, and TTG1 synergistically specify the expression of BANYULS and proanthocyanidin biosynthesis in Arabidopsis thaliana. Plant J 2004, 39(3):366-380.

13. Koes R, Verweij W, Quattrocchio F: Flavonoids: a colorful model for the regulation and evolution of biochemical pathways. Trends Plant Sci 2005, 10(5):236-242

14. Sainz MB, Grotewold E, Chandler VL: Evidence for direct activation of an anthocyanin promoter by the maize C1 protein and comparison of DNA binding by related Myb domain proteins. Plant Cell 1997, 9(4):611-625.

15. Rosinski JA, Atchley WR: Molecular evolution of the Myb family of transcription factors: evidence for polyphyletic origin. J Mol Evol 1998, 46(1):74-83.

16. Jin $\mathrm{H}$, Martin C: Multifunctionality and diversity within the plant MYBgene family. Plant Mol Biol 1999, 41(5):577-585.

17. Stracke $R$, Werber M, Weisshaar B: The R2R3-MYB gene family in Arabidopsis thaliana. Curr Opin Plant Biol 2001, 4(5):447-456.

18. Borevitz JO, Xia Y, Blount J, Dixon RA, Lamb C: Activation tagging identifies a conserved MYB regulator of phenylpropanoid biosynthesis. Plant Cell 2000, 12(12):2383-2394.

19. Aharoni A, De Vos CH, Wein M, Sun Z, Greco R, Kroon A, Mol JN, O'Connell AP: The strawberry FaMYB1 transcription factor suppresses anthocyanin and flavonol accumulation in transgenic tobacco. Plant $\mathrm{J}$ 2001, 28(3):319-332.

20. Jin H, Cominelli E, Bailey P, Parr A, Mehrtens F, Jones J, Tonelli C, Weisshaar B, Martin C: Transcriptional repression by AtMYB4 controls production of UV-protecting sunscreens in Arabidopsis. EMBO J 2000, 19(22):6150-6161.

21. Tamagnone L, Merida A, Parr A, Mackay S, Culianez-Macia FA, Roberts K Martin C: The AmMYB308 and AmMYB330 transcription factors from Antirrhinum regulate phenylpropanoid and lignin biosynthesis in transgenic tobacco. Plant Cell 1998, 10(2):135-154.

22. Dubos C, Le Gourrierec J, Baudry A, Huep G, Lanet E, Debeaujon I, Routaboul JM, Alboresi A, Weisshaar B, Lepiniec L: MYBL2 is a new regulator of flavonoid biosynthesis in Arabidopsis thaliana. Plant J 2008, 55(6):940-953.

23. Matsui $K$, Umemura Y, Ohme-Takagi M: AtMYBL2, a protein with a single MYB domain, acts as a negative regulator of anthocyanin biosynthesis in Arabidopsis. Plant J 2008, 55(6):954-967.

24. Espley RV, Hellens RP, Putterill J, Stevenson DE, Kutty-Amma S, Allan AC: Red colouration in apple fruit is due to the activity of the MYB transcription factor, MdMYB10. Plant J 2007, 49(3):414-427.

25. Allan AC, Hellens RP, Laing WA: MYB transcription factors that colour our fruit. Trends Plant Sci 2008, 13(3):99-102.
26. Gonzalez A, Zhao M, Leavitt JM, Lloyd AM: Regulation of the anthocyanin biosynthetic pathway by the $\pi \mathrm{G} 1 / \mathrm{bH} L \mathrm{H} / \mathrm{Myb}$ transcriptional complex in Arabidopsis seedlings. Plant J 2008, 53(5):814-827.

27. Mathews H, Clendennen SK, Caldwell CG, Liu XL, Connors K, Matheis N, Schuster DK, Menasco DJ, Wagoner W, Lightner J, Wagner DR: Activation tagging in tomato identifies a transcriptional regulator of anthocyanin biosynthesis, modification, and transport. Plant Cell 2003, 15(8):1689-1703.

28. Quattrocchio F, Wing J, Woude van der K, Souer E, de Vetten N, Mol J, Koes $\mathrm{R}$ : Molecular analysis of the anthocyanin2 gene of petunia and its role in the evolution of flower color. Plant Cell 1999, 11(8):1433-1444.

29. Borovsky Y, Oren-Shamir M, Ovadia R, De Jong W, Paran I: The A locus that controls anthocyanin accumulation in pepper encodes a MYB transcription factor homologous to Anthocyanin2 of Petunia. Theor Appl Genet 2004, 109(1):23-29.

30. Kobayashi S, Goto-Yamamoto N, Hirochika H: Retrotransposon-induced mutations in grape skin color. Science 2004, 304(5673):982.

31. Grotewold E, Athma P, Peterson T: Alternatively spliced products of the maize $\mathrm{P}$ gene encode proteins with homology to the DNA-binding domain of myb-like transcription factors. Proc Natl Acad Sci USA 1991, 88(11):4587-4591.

32. Saitoh K, Onishi K, Mikami I, Thidar K, Sano Y: Allelic diversification at the $C$ (OsC1) locus of wild and cultivated rice: nucleotide changes associated with phenotypes. Genetics 2004, 168(2):997-1007.

33. Mano H, Ogasawara F, Sato K, Higo H, Minobe $Y$ : Isolation of a regulatory gene of anthocyanin biosynthesis in tuberous roots of purple-fleshed sweet potato. Plant Physiol 2007, 143(3):1252-1268.

34. Schwinn K, Venail J, Shang Y, Mackay S, Alm V, Butelli E, Oyama R, Bailey P, Davies K, Martin C: A small family of MYB-regulatory genes controls floral pigmentation intensity and patterning in the genus Antirrhinum. Plant Cell 2006, 18(4):831-851.

35. Elomaa P, Uimari A, Mehto M, Albert VA, Laitinen RA, Teeri TH: Activation of anthocyanin biosynthesis in Gerbera hybrida (Asteraceae) suggests conserved protein-protein and protein-promoter interactions between the anciently diverged monocots and eudicots. Plant Physiol 2003, 133(4):1831-1842.

36. Xue B, Charest PJ, Devantier Y, Rutledge RG: Characterization of a MYBR2R3 gene from black spruce (Picea mariana) that shares functional conservation with maize C1. Mol Genet Genomics 2003, 270(1):78-86.

37. Palapol Y, Ketsa S, Lin-Wang K, Ferguson IB, Allan AC: A MYB transcription factor regulates anthocyanin biosynthesis in mangosteen (Garcinia mangostana L.) fruit during ripening. Planta 2009, 229(6):1323-1334.

38. Ban $Y$, Honda $C$, Hatsuyama $Y$, Igarashi M, Bessho H, Moriguchi T: Isolation and functional analysis of a MYB transcription factor gene that is a key regulator for the development of red coloration in apple skin. Plant Cell Physiol 2007, 48(7):958-970.

39. Takos AM, Jaffe FW, Jacob SR, Bogs J, Robinson SP, Walker AR: Lightinduced expression of a MYB gene regulates anthocyanin biosynthesis in red apples. Plant Physiol 2006, 142(3):1216-1232.

40. Nakatsuka T, Haruta KS, Pitaksutheepong C, Abe Y, Kakizaki Y, Yamamoto K, Shimada N, Yamamura S, Nishihara M: Identification and characterization of R2R3-MYB and bHLH transcription factors regulating anthocyanin biosynthesis in gentian flowers. Plant Cell Physiol 2008, 49(12):1818-1829.

41. Chagné D, Gasic K, Crowhurst RN, Han Y, Bassett HC, Bowatte DR, Lawrence TJ, Rikkerink EH, Gardiner SE, Korban SS: Development of a set of SNP markers present in expressed genes of the apple. Genomics 2008, 92(5):353-358.

42. Espley RV, Brendolise C, Chagne D, Kutty-Amma S, Green S, Volz R, Putterill J, Schouten HJ, Gardiner SE, Hellens RP, Allan AC: Multiple repeats of a promoter segment causes transcription factor autoregulation in red apples. Plant Cell 2009, 21(1):168-183.

43. Zonneveld BJM, Leitch IJ, Bennett MD: First nuclear DNA amounts in more than 300 angiosperms. Annals of Botany 2005, 96:229-244.

44. Zimmermann IM, Heim MA, Weisshaar B, Uhrig JF: Comprehensive identification of Arabidopsis thaliana MYB transcription factors interacting with R/B-like BHLH proteins. Plant J 2004, 40(1):22-34.

45. Sawa S: Overexpression of the AtmybL2 gene represses trichome development in Arabidopsis. DNA Res 2002, 9(2):31-34.

46. Hellens RP, Allan AC, Friel EN, Bolitho K, Grafton K, Templeton MD, Karunairetnam S, Gleave AP, Laing WA: Transient expression vectors for functional genomics, quantification of promoter activity and RNA silencing in plants. Plant Methods 2005, 1:13. 
47. Oosumi T, Gruszewski HA, Blischak LA, Baxter AJ, Wadl PA, Shuman JL, Veilleux RE, Shulaev V: High-efficiency transformation of the diploid strawberry (Fragaria vesca) for functional genomics. Planta 2006, 223(6):1219-1230.

48. Riechmann JL, Heard J, Martin G, Reuber L, Jiang C, Keddie J, Adam L, Pineda O, Ratcliffe OJ, Samaha RR: Arabidopsis transcription factors: genome-wide comparative analysis among eukaryotes. Science 2000, 290:2105-2110.

49. Shin R, Burch A, Huppert K, Tiwari S, Murphy A, Guilfoyle T, Schachtman D: The Arabidopsis transcription factor MYB77 modulates auxin signal transduction. Plant Cell 2007, 19(8):2440-2453.

50. Petroni K, Falasca G, Calvenzani V, Allegra D, Stolfi C, Fabrizi L, Altamura M, C T: The AtMYB11 gene from Arabidopsis is expressed in meristematic cells and modulates growth in planta and organogenesis in vitro. $J$ Exp Bot 2008, 59(6):1201-1213.

51. Wang S, Hubbard L, Chang Y, Guo J, Schiefelbein J, Chen JG: Comprehensive analysis of single-repeat R3 MYB proteins in epidermal cell patterning and their transcriptional regulation in Arabidopsis. BMC Plant Biol 2008, 8:81.

52. Cominelli E, Galbiati M, Vavasseur A, Conti L, Sala T, Vuylsteke M, Leonhardt N, Dellaporta S, C T: A guard-cell-specific MYB transcription factor regulates stomatal movements and plant drought tolerance. Curr Biol 2005, 15(13):1196-1200.

53. Liang YK, Dubos C, Dodd IC, Holroyd GH, Hetherington AM, Campbell MM: AtMYB61, an R2R3-MYB transcription factor controlling stomatal aperture in Arabidopsis thaliana. Curr Biol 2005, 15(13):1201-1206.

54. Gonzalez A, Mendenhall J, Huo Y, Lloyd A: TTG1 complex MYBs, MYB5 and TT2, control outer seed coat differentiation. Dev Biol 2009, 325(2):412-421.

55. Abe H, Urao T, Ito T, Seki M, Shinozaki K, Yamaguchi-Shinozaki K: Arabidopsis AtMYC2 (bHLH) and AtMYB2 (MYB) function as transcriptional activators in abscisic acid signaling. Plant Cell 2003, 15(1):63-78.

56. Zhu J, Verslues PE, Zheng X, Lee BH, Zhan X, Manabe $Y$, Sokolchik I, Zhu Y, Dong CH, Zhu JK, Hasegawa PM, Bressan RA: HOS10 encodes an R2R3type MYB transcription factor essential for cold acclimation in plants. Proc Natl Acad Sci USA 2005, 102(28):9966-9971.

57. Agarwal M, Hao Y, Kapoor A, Dong CH, Fujii H, Zheng X, Zhu JK: A R2R3 type MYB transcription factor is involved in the cold regulation of CBF genes and in acquired freezing tolerance. J Biol Chem 2006, 281(49):37636-37645.

58. Vailleau F, Daniel X, Tronchet M, Montillet JL, Triantaphylides C, Roby D: A R2R3-MYB gene, AtMYB30, acts as a positive regulator of the hypersensitive cell death program in plants in response to pathogen attack. Proc Natl Acad Sci USA 2002, 99(15):10179-10184.

59. Mengiste $T$, Chen $X$, Salmeron J, Dietrich R: The BOTRYTIS SUSCEPTIBLE1 gene encodes an R2R3 MYB transcription factor protein that is required for biotic and abiotic stress responses in Arabidopsis. Plant Cell 2003, 15(11):2551-2565.

60. Kawamura M, Ito S, Nakamichi N, Yamashino T, Mizuno T: The function of the clock-associated transcriptional regulator CCA1 (CIRCADIAN CLOCKASSOCIATED 1) in Arabidopsis thaliana. Biosci Biotechnol Biochem 2008, 72(5):1307-1316

61. Ballesteros ML, Bolle C, Lois LM, Moore JM, Vielle-Calzada JP, Grossniklaus U, Chua NH: LAF1, a MYB transcription activator for phytochrome A signaling. Genes Dev 2001, 15(19):2613-2625

62. Lu CA, Ho TH, Ho SL, Yu SM: Three novel MYB proteins with one DNA binding repeat mediate sugar and hormone regulation of alpha-amylase gene expression. Plant Cell 2002, 14(8):1963-1980.

63. Sonderby IE, Hansen BG, Bjarnholt N, Ticconi C, Halkier BA, Kliebenstein DJ: A systems biology approach identifies a R2R3 MYB gene subfamily with distinct and overlapping functions in regulation of aliphatic glucosinolates. PLOS ONE 2007, 2(12):e1322.

64. Malitsky S, Blum E, Less H, Venger I, Elbaz M, Morin S, Eshed Y, Aharoni A: The transcript and metabolite networks affected by the two clades of Arabidopsis glucosinolate biosynthesis regulators. Plant Physiol 2008, 148(4):2021-2049.

65. Stracke R, Ishihara H, Huep G, Barsch A, Mehrtens F, Niehaus K, Weisshaar B: Differential regulation of closely related R2R3-MYB transcription factors controls flavonol accumulation in different parts of the Arabidopsis thaliana seedling. Plant J 2007, 50(4):660-677.
66. Li J, Yang X, Wang Y, Li X, Gao Z, Pei M, Chen Z, Qu LJ, Gu H: Two groups of MYB transcription factors share a motif which enhances transactivation activity. Biochem Biophys Res Commun 2006, 341(4):1155-1163.

67. Grotewold E, Sainz MB, Tagliani L, Hernandez JM, Bowen B, Chandler VL: Identification of the residues in the Myb domain of maize $\mathrm{C} 1$ that specify the interaction with the bHLH cofactor R. Proc Natl Acad Sci USA 2000, 97(25):13579-13584.

68. Bogs J, Jaffe FW, Takos AM, Walker AR, Robinson SP: The grapevine transcription factor VvMYBPA1 regulates proanthocyanidin synthesis during fruit development. Plant Physiol 2007, 143(3):1347-1361.

69. Fornale S, Sonbol FM, Maes T, Capellades M, Puigdomenech P, Rigau J, Caparros-Ruiz D: Down-regulation of the maize and Arabidopsis thaliana caffeic acid O-methyl-transferase genes by two new maize R2R3-MYB transcription factors. Plant Mol Biol 2006, 62(6):809-823.

70. Tohge T, Nishiyama Y, Hirai MY, Yano M, Nakajima J, Awazuhara M, Inoue E, Takahashi H, Goodenowe DB, Kitayama M, Noji M, Yamazaki M, Saito K: Functional genomics by integrated analysis of metabolome and transcriptome of Arabidopsis plants over-expressing an MYB transcription factor. Plant J 2005, 42(2):218-235.

71. Quattrocchio F, Verweij W, Kroon A, Spelt C, Mol J, Koes R: PH4 of Petunia is an R2R3 MYB protein that activates vacuolar acidification through interactions with basic-helix-loop-helix transcription factors of the anthocyanin pathway. Plant Cell 2006, 18(5):1274-1291.

72. Matus JT, Aquea F, Arce-Johnson P: Analysis of the grape MYB R2R3 subfamily reveals expanded wine quality-related clades and conserved gene structure organization across Vitis and Arabidopsis genomes. BMC Plant Biol 2008, 8:83.

73. Antonius-Klemola K, Kalendar R, Schulman AH: TRIM retrotransposons occur in apple and are polymorphic between varieties but not sports. Theor App/ Genet 2006, 112(6):999-1008.

74. Potter D, Eriksson T, Evens RC, Oh S, Smedmark JEE, Morgan DR, Kerr M, Robertson KR, Arsenault M, Dickinson TA, Campbell CS: Phylogeny and classification of Rosaceae. PI Syst Evol 2007, 266:5-43.

75. Chagné D, Carlisle CM, Blond C, Volz RK, Whitworth CJ, Oraguzie NC, Crowhurst RN, Allan AC, Espley RV, Hellens RP, Gardiner SE: Mapping a candidate gene (MdMYB10) for red flesh and foliage colour in apple. BMC Genomics 2007, 8:212.

76. Toufektsian MC, de Lorgeril M, Nagy N, Salen P, Donati MB, Giordano L, Mock HP, Peterek S, Matros A, Petroni K, Pilu R, Rotilio D, Tonelli C, de Leiris J, Boucher F, Martin C: Chronic dietary intake of plant-derived anthocyanins protects the rat heart against ischemia-reperfusion injury. J Nutr 2008, 138(4):747-752.

77. Chang S, Puryear J, Cairney J: A simple and efficient method for isolating RNA from pine trees. Plant Mol Biol Rep 1993, 11:113-116.

78. Hood EEGSB, Melchers LS, Hoekema A: New Agrobacteruim Helper plasmids for gene transfer to plants. Transgenic Research 1993, 2: 208-218.

79. Hellens RP, Edwards EA, Leyland NR, Bean S, Mullineaux PM: pGreen: a versatile and flexible binary Ti vector for Agrobacterium-mediated plant transformation. Plant Mol Biol 2000, 42(6):819-832.

80. Kumar S, Tamura K, Nei M: MEGA3: Integrated software for Molecular Evolutionary Genetics Analysis and sequence alignment. Brief Bioinform 2004, 5(2):150-163.

doi:10.1186/1471-2229-10-50

Cite this article as: Lin-Wang et al:: An R2R3 MYB transcription factor associated with regulation of the anthocyanin biosynthetic pathway in Rosaceae. BMC Plant Biology 2010 10:50. 